Journal of Agricultural Sciences
(Tarim Bilimleri Dergisi)

\title{
Digital Transformation for Sustainable Future - Agriculture 4.0: A review
}

\author{
Mehmet Ali DAYIOĞLU ${ }^{\text {a* }} \mathbb{D}$, Ufuk TÜRKER ${ }^{a}$ (i)

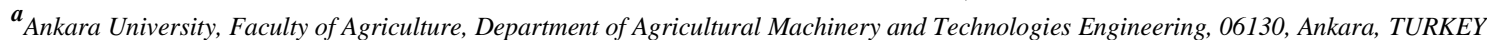

ARTICLE INFO

Research Article

Corresponding Author: Mehmet Ali DAYIOĞLU, E-mail: dayioglu@agri.ankara.edu.tr

Received: 24 August 2021 / Revised: 29 October 2021 / Accepted: 01 November 2021 / Online: 04 December 2021

\section{ABSTRACT}

In the last few years, while the COVID-19 pandemic affects food supply chains around the world, the agriculture sector also has faced many global problems, such as global warming, environmental pollution, climate change, and weather disasters. It has known that technological opportunities are available for human beings to get out of these predicaments, solving the interconnections between food-water-energyclimate nexus, and achieving agricultural transformation from traditional to digital.

The aim of this review is to gain holistic solutions in a systematic view, based on water-energy-food resources to agricultural digital transformation that will play role in sustainable development. The transition from primitive to digital is given with road maps covering agricultural and industrial revolutions at four stages on timeline. Digital agriculture combined under precision agriculture and Agriculture 4.0 are handled based on domains covering monitoring, control, prediction, and logistics. Digital technologies are explained with application examples such as the Internet of Things (IoT), cloud computing, big data, artificial intelligence, decision support systems, etc. Wearable sensor technologies, real-time monitoring systems tracking whole conditions of animals in livestock, the IoT-based irrigation and fertilization systems that help enhance the efficiency of irrigation processes and minimize water and fertilizer losses in agricultural fields and greenhouses, blockchain-based electronic agriculture, and solutions based on drones and robotics that reduce herbicide and pesticide use are handled systematically. Moreover, renewable energy technologies to be provided synergy between technologies such as agrivoltaics and aquavoltaics combining food and energy production in rural are explained, besides solar-powered pivot and drip irrigation systems and environmental monitoring systems. As a result, for a sustainable future, technological innovations that increase crop productivity and improve crop quality, protect the environment, provide efficient resource use and decrease input costs can help us facing in agriculture of today overwhelm many the economic, social, and environmental challenges.

Keywords: Smart farming, Digital transformation, Sustainable development, Blockchain, Artificial intelligence in agriculture, Information technologies

(C) Ankara University, Faculty of Agriculture

\section{Introduction}

Agriculture producing food, feed, fibers, fuel, and raw materials by cultivating plants and breeding livestock is one of the oldest and most vital sources in the civilization of human beings and in the economic growth of each country that forms the backbone. The latest FAO report (FAO 2017a) emphasized that the world's population will be near 10 billion by 2050, and agriculture will be a more deeply key role each day for the continuation of life and socio-economic development. It has been predicted that increases in food, water and energy demands will be 60\% (FAO 2012), 55\% (OECD 2012) and 50\% (EIA 2019) by 2050, respectively.

At global level, while consuming approximately $30 \%$ of the total energy in during agri-food production, this causes nearly one third of GHG emissions (FAO 2020; Platis et al. 2019). Global food systems are responsible for about $25 \%$ to $42 \%$ of all global greenhouse gas (GHG) emissions emitted during production, processing, transportation, packaging, consuming, and disposing of food according to a study carried out for the years 1990-2015 (Crippa et al. 2021).

While agriculture is the pillar of food security, it is the largest user of freshwater that affects energy security (Tian et al. 2018). Global projections indicate that the demand for clean water, energy, and food will increase significantly in the coming years (Hoff 2011).

Today, agriculture accounts for $70 \%$ of global freshwater use and $34 \%$ of land use, putting unsustainable pressure on our natural resources (Lee 2019). Also, water use is 80-90\% in the agri-food sector including irrigation (FAO 2016; Bundschuh et al. 2107). But irrigation only amounts can reach as much as 95 percent in some developing countries (Mohtar \& Daher 2016; FAO 2017b). 
Water plays a key role in socioeconomic development that strongly connects food and energy (Daher et al. 2019). Industry consumes $22 \%$ of water resources, most of which is used for cooling thermal processes in electricity generation (EIA 2016). If action is not taken now, such expanding gap between resource supply and demand would be further occurs deep problems related to continuous population growth, climate change and extreme climatic events, socio-economic development.

Both agricultural activities and production of food consume at large amounts of water and energy (Roidt \& Avellán 2019). Therefore, water, energy, and food (WEF) are three strategic resources for the sustainable development of national economies (Purwanto et al. 2019). It is becoming increasingly difficult to ensure sufficient WEF with the impact of climate change, population growth, changing diets, urbanization, and aging (Zhang et al. 2018; Alcon et al. 2019).

Agriculture is also a major source of water pollution from nutrients, pesticides, and other contaminants, which if unmanaged can lead to significant social, economic, and environmental costs (FAO 2017). In the recent decades, agriculture is beset by two major discrepancies: the first conflict is between resources supply and demand, while the second conflict is between economic development and environmental protection (Yue \& Guo 2021).

In recent years, global climate change has caused many irregular and extreme weather events in many parts of the world (Li et al. 2021). As a result of global warming, intense drought, severe hurricanes and storms, and extreme floods have begun to be experienced intensely in different parts of the world (FAO 2021). In addition, the success of crop and animal production varies depending on the short and long-term complex environmental effects of global warming and climate change (Hatfield et al. 2011). In many places of the world, plants are negatively affecting by climate conditions that are very hot or very cold, and wet or dry (Hatfield et al. 2015; FAO 2019). Rising seed, fertilizer prices and wages, epidemic and vegetative diseases, trade wars, flash floods, heatwaves, and other weather changes negatively affect agriculture. To meet these challenges and meet the demands of the future, countries need to develop policies and programs in a sustainable way.

In a report published by UNECE (2021), it was emphasized that demographic, economic, social, and climatic changes, were all exerting increasing pressure on natural resources, including through a seemingly ever-growing global demand for energy, food, and water that threatens the ecosystems. As a solution, the key to shifting towards sustainable development was highlighted that lies in the strategic decisions to be taken regarding natural resources, which need to be better valued and more responsibly managed.

Among literature studies reviewed, no article has been found that analyzes in view of systematic and holistic related to digital transition and transformation for a sustainable future in agriculture. Most of the literature focuses on individual integration of Agriculture 4.0 technologies and their applications in different sectors. This review aims to close the study gap with a systematic approach, analyzing digital technologies in agriculture for a sustainable future based on "Energy-Water-Food" Nexus.

The rest of this paper is organized as follows. Section 2 gives the development roadmap of industrial revolutions and agricultural revolutions. Section 3 introduces sustainable food and agriculture, water-energy-food nexus, and digital transformation concepts. Section 4 discusses precision agriculture and Agriculture 4.0 topics under the smart farming heading, covering novel technologies, digital transition and challenges. Section 5 introduces renewable energy and environmental technologies, new combined solutions; and discussion and conclusions are presented in the $6^{\text {th }}$ and $7^{\text {th }}$ sections, respectively.

\section{Agricultural and Industrial Revolutions}

The expression Industry 4.0 was used to point out new tsunami of technological progress that was defined in 2015 by Schwab as the "fourth industrial revolution" (Schwab 2015). While the first industrial revolution in the 18th century was characterized by transition from an agricultural economy to an industrial economy, the second industrial revolution covered from water and steam power to electric power (Adebanjo et al. 2020).

The evolution of agriculture, from the primitive level to the advanced level of today, took place gradually over time. Figure 1 shows together schematic timelines of both industrial revolutions and agricultural revolutions. Technological developments in agriculture are divided into 4 long-term and named the transformation from Agriculture 1.0 to Agriculture 4.0 (Liu et al. 2021). 


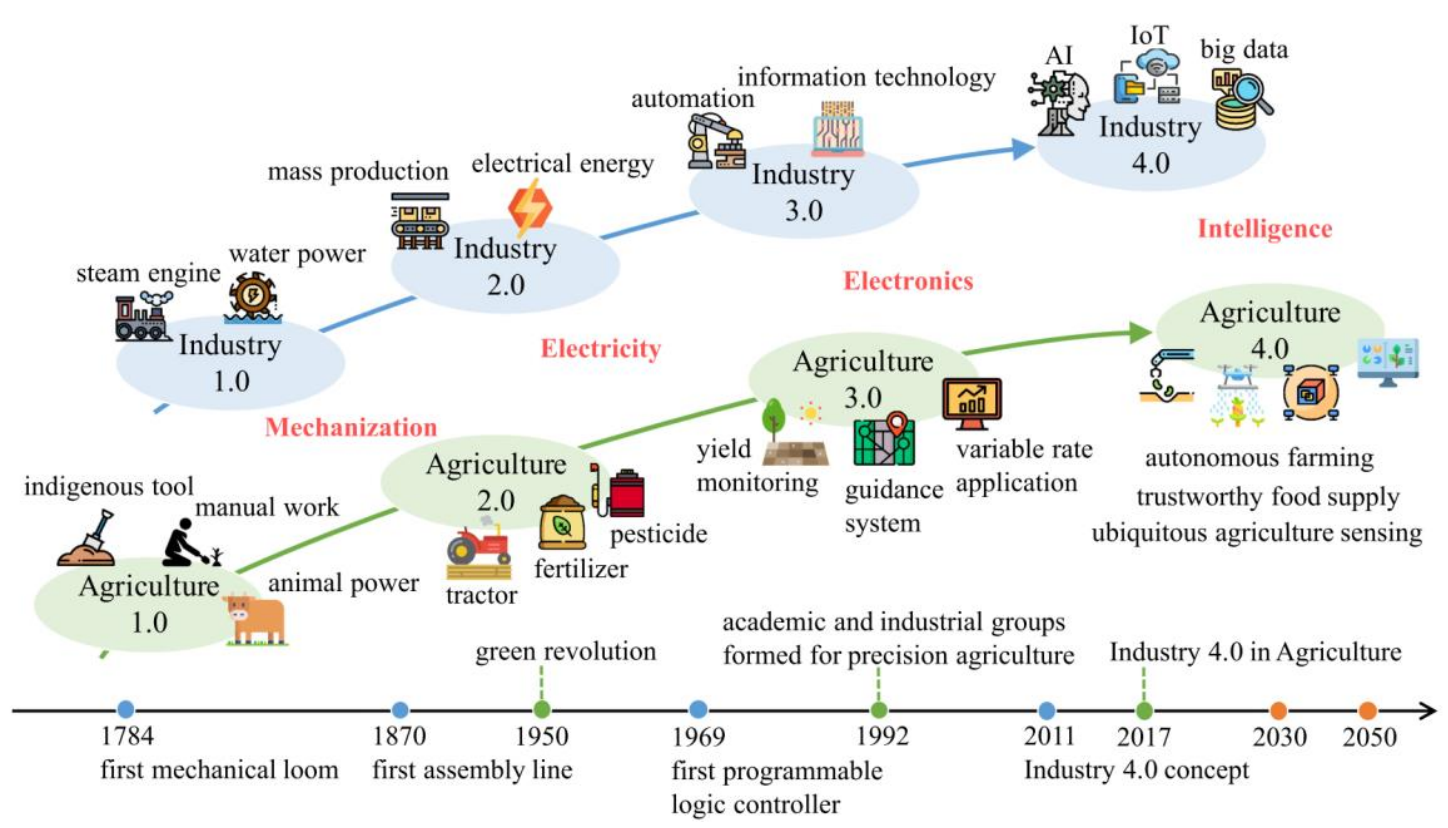

Figure 1- Time lines of industrial revolutions and agricultural revolutions (Liu et al. 2021)

Period that is conventional agriculture practices from antique ages when farmers mostly used domestic hand tools for cultivation mainly relying on manpower and animal forces to the end of the $19^{\text {th }}$ century is accepted as Agriculture 1.0.

Agriculture 2.0 is referred as the period that is the increase food production and reduce hand jobs between 1784 and almost 1870, when agricultural machinery was used for soil tillage, sowing, weeding, irrigation, and harvesting (Liu et al. 2021).

After passing from the main steam power to oil and gas power, the industry 2.0 period of the $20^{\text {th }}$ century started. Due to developments in the energy and transportation sectors, agricultural products were started shipping to long distances. Resulting, far communities connected together and new agriculture markets emerged that farmers can sell their produce (Liu et al. 2021). The first assembly line that significantly increased efficiency and productivity was set up for mass production (Zhai et al. 2020). The first agricultural mass production was applied to meat production in livestock. All these developments provided making for large-scale intensive animal farming.

"The Green Revolution" era, namely Agriculture 2.0, is the phase of farming that began in the late 1950s when new agronomic management practices, new synthetic pesticides, and fertilizers were used in agricultural fields and various machines were manually operated by farmers (Zambon et al. 2019). Thus, yields, productivity, and returns increased at all levels (CEMA 2017a). Although increased productivity and improved efficiency were achieved thanks to mechanization, all of them, overconsumption of fossil fuels, water, and chemicals caused the destruction of the environment. Indeed, still today, mankind continues the devastations with effects so great that it changes the climate in many parts of the world. Furthermore, the first programmable logic controller (PLC) was used in industry in 1969, depending on electronics and on information technology (Yülek 2018).

Agriculture 3.0, called also "Precision Farming" emerged thanks to advances carried out on computing and electronics. These developments provided saving on energy in machinery use of and saving on the water in irrigation, and reducing in use of chemicals in the field and, thanks to increasing operational performance of agricultural systems (Ahmad \& Nabi 2021). According to the definition of the International Society of Precision Agriculture (PA), "Precision Agriculture is a management strategy that gathers, processes, and analyses temporal, spatial, and individual data and combines it with other information to guide site, plant, or animal-specific management decisions to improve resource efficiency, productivity, quality, profitability and sustainability of agricultural production.” (ISPA 2021).

Although agriculture has been affected from every era of industrial revolutions, it should be noted the digital transformation in the agriculture sector started with PA. Today, the agricultural sector is experiencing a new revolution, called Agriculture 4.0 from with the affecting of digital technologies also in "Industry 4.0" entered our life in 2011.

\section{Sustainability for Future}

United Nations (UNs) called for a universal action plan related to Sustainable Development Goals (SDGs) adopted on 25 September 2015 to end poverty, protect the planet, and improve the lives of everyone, everywhere. The 17 goals are part of the 2030 Agenda for Sustainable Development. This agenda sets out a 15-year (2016-2030) plan to achieve the goals. These were 
planned to help measure progress in each of the 193 countries that agreed to work towards achieving the goals. SDGs 17 targets are illustrated holistically in Figure 2 (United Nations 2015).

As highlighted in report prepared by The World in 2050 initiative, governments that signed the 2030 agenda of the Sustainable Development Goals (SDGs) and the Paris Agreement on Climate Change are calling for profound transformations that will require complementary actions from civil society, science and business (TWI2050 2018).
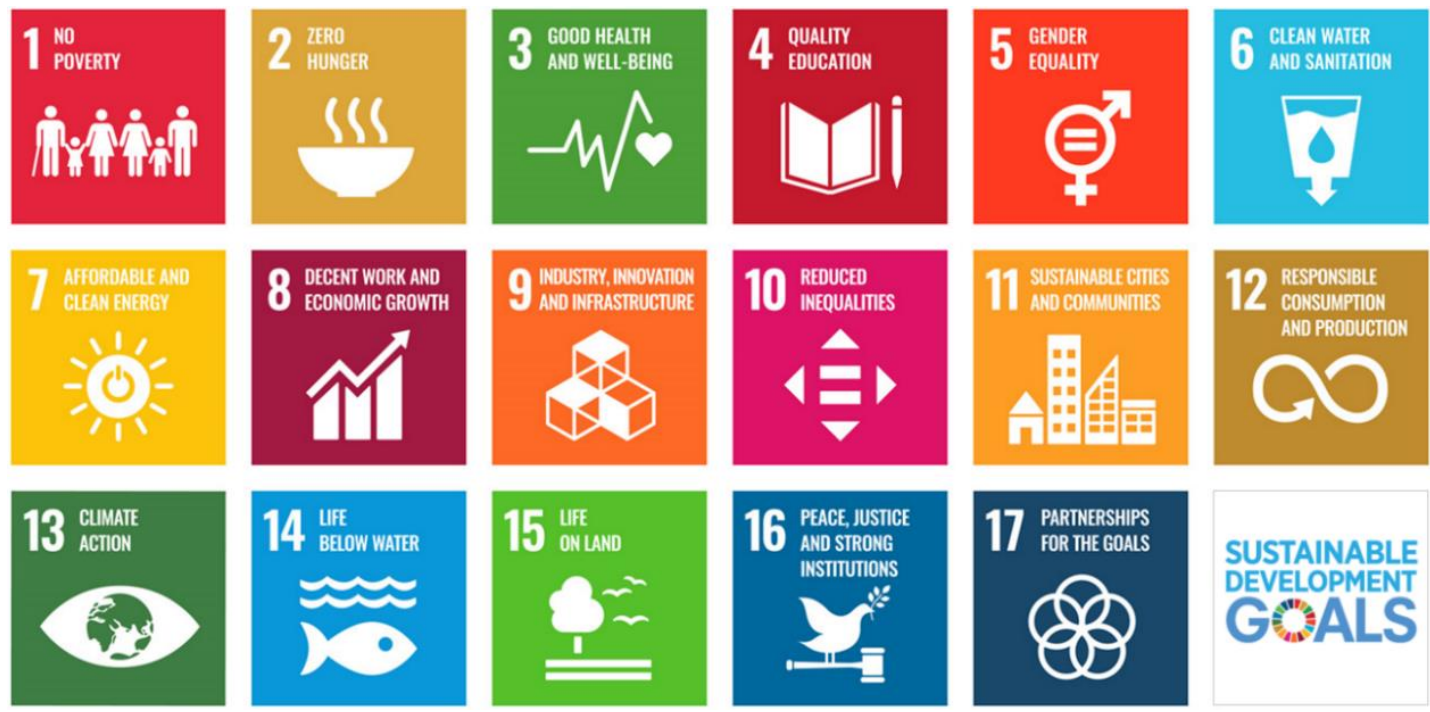

Figure 2- Sustainable Development Goals numbered according to icons accepted by United Nations (United Nations 2015)

Setting off to carry out the activities in The World in 2050 initiative, Sachs et al. (2019) presented six SDG transformations to achieve SDG targets. Among which, Transformation 4 has taken attention as one of the key parts covering sustainable food, land, water, and oceans. Transformation 6 covers the digital revolution for sustainable development comes forward as a foremost force that makes a difference, also it has been also pointed out as the Fourth Industrial Revolution.

In Trends in Biotechnology published in 2021, it emphasized that biotechnology to be coupled with digital technologies will play a key role in transforming current land-use systems in the future (Goh et al. 2021).

\subsection{Sustainable food and agriculture}

The FAO has established five basic principles that will provide to become increasingly productive and sustainable, building a production system that works in favour of the ecosystem, satisfying human needs to achieve 2030 SDG targets. FAO's five basic principles are: (1) Increasing productivity, employment, and value addition in food systems, (2) Protecting and enhancing natural resources, (3) Improving livelihoods and fostering inclusive economic growth, (4) Enhancing the resilience of people, communities, and ecosystems, and (5) Adapting governance to new challenges (FAO 2018).

Moreover, the 20 practical and interconnected actions integrated by FAO (2018) are prepared for decision-makers to provide transformations related to the 2030 Agenda SDGs.

The 2030 SDGs comprise the aims related to food (SDG 2), water (SDG 6), energy (SDG 7), climate change (SDG 13), and ecosystem (SDG 15). Policies and programs managers to be developed by managers will sign managing of resources in future in the way a more sustainable one. Nevertheless, there are many operational difficulties. Holistic systematic analyses are needed to obtain comprehensive solutions covering problems related to the water-energy-food-climate. Future farming will be built on four main pillars are follows (1) Improving productivity, (2) Rational use of resources, (3) Adaptation to climate change, and (4) Avoidance of food waste (FAO 2018).

\subsection{Water-Energy-Food Nexus}

Energy, water and food security have been identified as three of the key resources in achieving the United Nations' sustainable development goals (Babatunde et al. 2019). Therefore, the water-energy-food nexus has been proposed as a conceptual tool for achieving sustainable development. Many developing countries has faced many challenges to meet the demands increasing for healthy food, clean water and green energy due to the climate change. An effective solution can only be achieved through sustainable use of vital resources such as land, water, and energy (Rasul \& Sharma 2016). 
Water, energy, and food are resources that are unavoidably connected with each other. Impacts on only one resource can also cause changes in the other ones. The increasing global population, energy demands, freshwater resources, and food supply emphasize the significance of this topic. The Water-Food-Energy (WEF) Nexus concept was introduced by Hoff in the World Economic Forum held in the Bonn in 2011 to take measures pointing out the problems the world may face and to address the links between water and economic development (Hoff 2011). In recent years, the WEF nexus has become an independent technical term due to its growing popularity. The interdependent and complex interactions of these three basic resources are called as the water-energy-food nexus (Zhang and Vesselinov 2016; Bieber et al. 2018). Solutions of challenges concerning food, water, and energy have to be planned to meet current and future socio-economic demands at local, regional, national, and global scales for sustainable development (Bazilian et al. 2011; FAO 2014; Howells et al. 2013; IRENA 2015; Cevher 2019; Namany et al. 2021). Figure 3 shows connections water-energy-food nexus, interactions among WEF.

There are technological solutions based on nexus models for rural and urban fields (Lehmann 2018), sensor applications (Abegaz et al. 2018), renewable energy (IRENA 2015), and greenhouse monitoring (Asolkar \& Bhadade 2015). Moreover, if knowing the interconnections between the three elements of the Nexus, it can be determined which resource should be shared in what proportion for sustainable production, how taking temporal and spatial strategical decisions. (Tian et al. 2018; Zhang et al. 2018; Ravar et al. 2020, Norouzi \& Kalantari 2020; Keyhanpour et al. 2021; Yue et al. 2021).

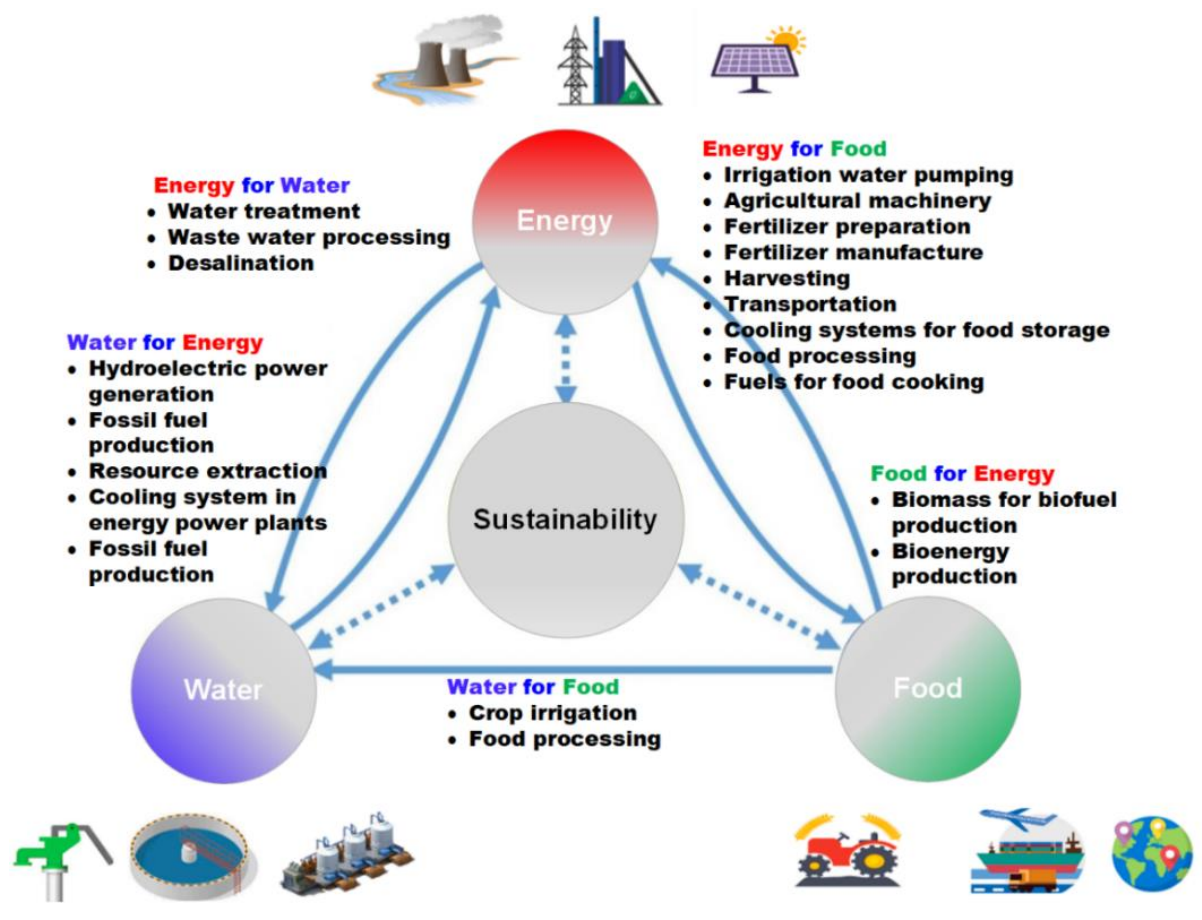

Figure 3- Water-energy-food nexus, interactions among WEF (modified from Bieber 2018).

\subsection{Digital Transformation}

According to FAO and World Bank reports, digital transformation can be used to solve challenges that are faced in agriculture and in rural areas (WB 2019; Trendov et al. 2019). Thanks to a well-planned transition towards smart farming (Klerkx \& Rose 2020), this transformation can contribute to agri-food systems (Klerkx and Begemann 2020). Digital transformation is a concept that defines the process of finding solutions to social and sectoral needs with the integration of digital technologies, and accordingly the development and change of workflows and culture (ElMassaha \& Mohieldin 2020). Digitalization is defined as the socio-technical process providing with using digital innovations. In the agricultural sector, numerous notions have emerged to define different forms of digitalization in agri-food production systems (Klerkx et al. 2019).

These are Precision Farming (McBratney et al. 2005; Aubert et al. 2012; Eastwood et al. 2017), Smart Farming (Wolfert et al. 2017), Agriculture 4.0 (Rose \& Chilvers 2018; De Clercq et al. 2018; Zambon et al. 2019; Zhai et al. 2020; Raj et al. 2021; Rijswijk et al. 2021; Rose et al. 2021). Moreover, synonyms of Agriculture 4.0 are "Numerical Agriculture" (Agriculture Numérique) in France (Klerkx et al. 2019), "Smart Farming" in many countries of the European Union, "Digital Agriculture" in Australia and New Zealand (Keogh \& Henry 2016; Shepherd et al. 2018; Fielke et al. 2020; Fleming et al. 2021). These concepts have defined as the "Digital Agricultural Revolution" by Food and Agriculture Organization (FAO) (Trendov et al. 2019)

According to CEMA (2018), Digital Farming is the transformation from Precision Farming to end to end connectable, knowledge-based farm production systems. CEMA explains that Digital Farming has a similar structure to Industry 4.0. However, there are many aspects of production parameters in agriculture that are different from industry. Agriculture is mostly 
defined with environmental and biological factors, and therefore its physical specifications should be basically considered (CEMA 2017a; 2017b).

Lioutas et al. (2021) presented the beneficial and negative aspects of digitalization. They also indicated the necessity to develop new approaches based on science in terms of societal impacts in the evolution of digital agriculture.

Pylianidis et al. (2021) reported a review on digital twins in agriculture in the period 2017-2020. They defined the unique characteristics of agricultural digital twins and pointed out that digitalization will provide multiple gains in terms of productivity and sustainability to the agricultural sector.

Fielke et al. (2019) explained that more comprehensive effects due to agricultural innovation and digitalization and pointed out that the main themes covering socio-technical dimensions of digitalization in agricultural production practices are connectivity, transparency, and governance.

Four key technologies that will be an active role in the future of digital farming are (1) vision and sensors, (2) automation and robotics (3) digitization and big data, (4) biological actors. At the heart of all these key technologies is the achievement of high efficiency in connectivity (Berger 2019).

\subsubsection{Connectivity}

Agricultural digital transformation is one of the topics that have political priority on a global scale (WB 2017; WB 2019; Trendov et al. 2019). According to the European Commission Report (EC 2017), one of the targets of the EU is to connect farmers end to end to the digital economy to succeed in the sustainable evolving of food and farming.

The digital connectivity in agricultural knowledge networks and agro-food value exchange will increase using novel tools such as digital hardware and software (Fielke et al. 2019). As shown in Figure 4, all three of these technologies-sensors, robotic automation, and digital data work together and are enabled by adequate connectivity as well as advances in edge computing and the cloud. At the heart of all these key technologies is the achievement of high efficiency in connectivity (Berger 2019).

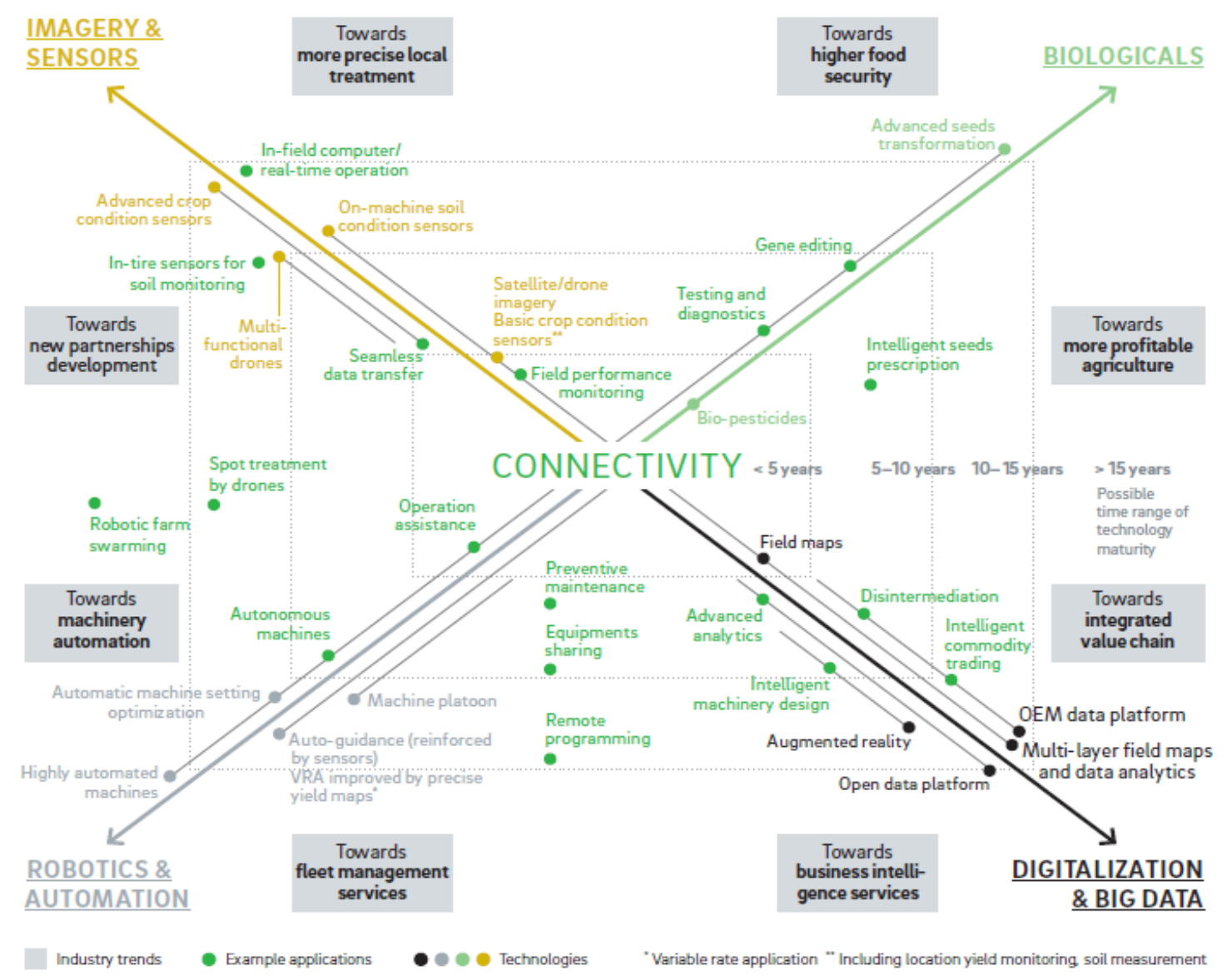

Figure 4- Four key technology levers to drive improvements to the farm economy and shape a new agricultural ecosystem - Agricultural industry technology map (Berger 2019) 


\subsubsection{Transparency}

Transparency in agricultural practices is important for all stakeholders in the agricultural sector including consumers, and regulators, in terms of deep connectivity and informational interaction between them (Fielke et al. 2019). Agricultural knowledge and advice networks digitalized will be crucial in terms of the transformation of agricultural innovation (Wolfert et al. 2017). Digital information flows transfer with transparency to everywhere will provide trust between farmers themselves and interactions with technologies (Kelton et al. 2008; Sligo \& Massey 2007). Transparency is need due to providing informational interaction with extensive connectivity between them (Wolfert et al. 2017).

\subsubsection{Governance}

It is known that challenges appear in balancing the priorities in terms of sustainable development in the agriculture sector as agri-food systems digitalize. In order to solve these, planning between public and private organizations will require (Carolan 2018; Regan 2019), considering socio-ethical factors to meet public and private goals in the agricultural sector (Fielke et al. 2019). Past experiences in agricultural decision support systems have seen that without the contributions of all stakeholders in the agricultural sector including social systems it will not be a sufficient solution (Fielke et al. 2018; Klerkx et al. 2017).

\section{Smart Farming}

Improvements in both hardware and software technology open a new chapter in agriculture, especially when it comes to sensors, biologicals, robotic \& automation, and digital data. PA is a part of smart farming technologies including agricultural management, information systems, and automation and robotics (Balafoutis et al. 2020; Klerkx et al. 2019; Rose \& Chilvers 2018).

\subsection{Precision Agriculture}

PA is the management of spatial and temporal variability through using advanced technologies to precisely match agricultural inputs to increase economic gains and lessen environmental impacts.

PA not only offers solutions to address many of the problems posed, exacerbated and exposed by this global crisis, it also has the potential to be an invaluable tool for rebuilding and strengthening the efficient and sustainable food systems of tomorrow. Prior to PA, farmers homogeneously managed their inputs such as seed, fertilizer, pesticide and irrigation despite existing withinfield variability in soil properties, crop stress and crop yield. Beginning in the 1990s, after the emergence of PA, farmers were able to divide their heterogeneous areas into smaller units that were relatively homogeneous. Knowing all the historical data of an area can help growers adopt a PA approach and adjust their input to benefit their land, increase profitability and reduce their overall environmental impact. PA offers the use of satellite technologies that allow real-time management of crops, fields and animals (Talepbour et al. 2015).

In the light of the developments it has shown from the emergence of PA to the present day, it develops agricultural management by making use of various perspectives. These perspectives are listed below.

a) Agronomic perspective: considering the real needs of the crop in the regulation of cultural practices (for example; better fertilization management).

b) Technical perspective: establishing better time management at farm level (for example; planning of agricultural activities).

c) Environmental perspective: reducing agricultural effects (to more accurately estimate the soil's need for nitrogen to limit nitrogen flow).

d) Economic perspective: increasing productivity or reducing the amount of input, increasing the efficiency of the yield (for example; making nitrogen fertilization application at low cost).

Recently, various technologies related to PA have developed technologies like GPS systems, yield mapping, smart sensors, and automatic steering systems. As expected, these systems were developed for the farmer to increase yields, save nutrients and so as to make efficient sensing and decision support systems that can increase profitability on the farm and reduce negative environmental impact. PA supports reduced tillage and other cost and labor-saving novel technologies. Along with the latest developments in semi-autonomous systems and agricultural robots in this process, it seems that the process has accelerated among farmers. Figure 5 shows the connections between different technical systems and sensors, especially from geolocation and sensing systems to decision support, variable-rate operation, and route planning among emerging technologies in PA (Pedersen 2017).

Frontier technologies used in PA for long time have four main phases that span almost all agricultural applications. These four main stages and related technologies (Balafoutis et al. 2020); 
1. Guidance technologies- These include all types of automatic guidance for tractors and self-propelled agricultural machinery such as driver assistance, controlled traffic in agriculture, developed based on hardware and software.

2. Information management- Measurement is essential for accurate farming and better control results. Measurement systems consist of sensors that can be mounted on ground-based stations and attached to aerial or satellite platforms. They collect spatial information including soil mapping, canopy mapping, and yield mapping, also soil moisture mapping. Knowledge management will enable farmers to perform PA more efficiently and comfortably. If the connection between the digital and the physical farm is not made right, there can always be a shortage of precision farming among farmers.

3. Application technologies- These involve technologies such as variable rate irrigation and variable rate application technologies for nutrients, crop protection agents, irrigation, seeding, and precision weed control, developed based on hardware and software.

4. Data analysis technologies- These are used for the analysis of data gathered through data collection. Related technologies are:

- Management zone definition

- Decision support systems (DSS)

- Farm management information systems (FMS)

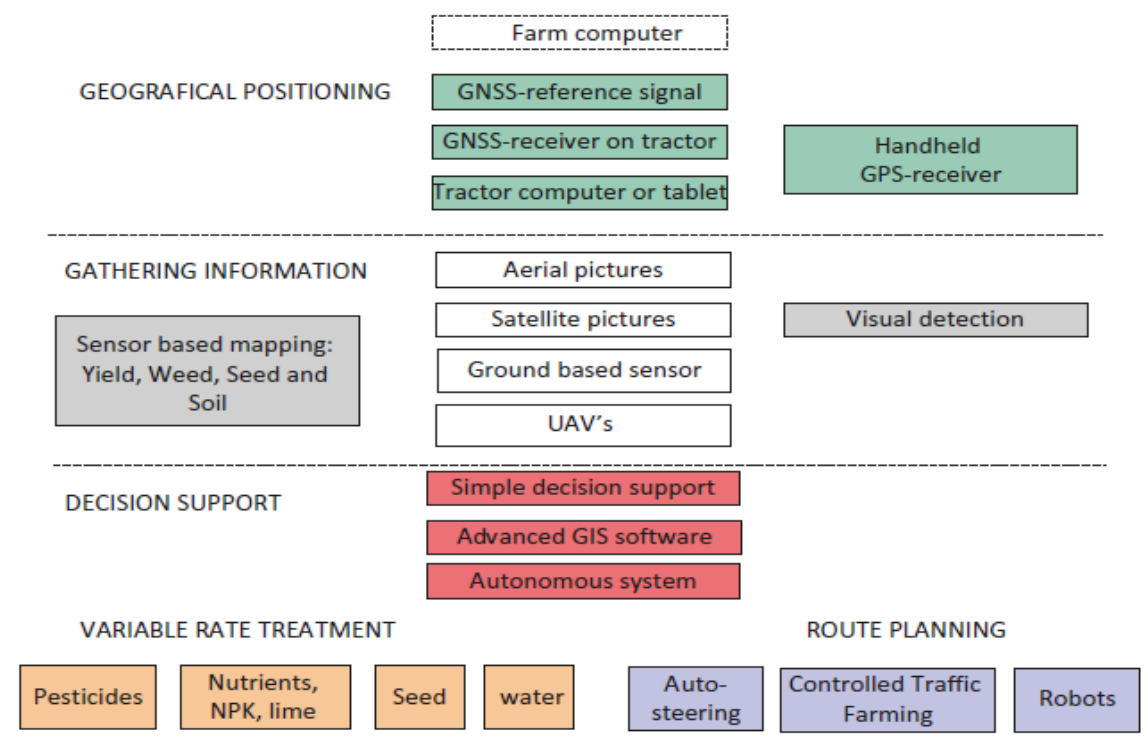

Figure 5- Major digital systems used in precision agriculture (Pedersen 2017)

International experiences and survey studies show that Aided Steering Systems (ASS) tend to be the first technologies adopted by farmers, due to their relative simplicity and the tangible benefits in terms of reduced fuel consumption and inputs as well as increased labour productivity (less driver fatigue, working during night, etc.) (Say et al. 2017). Recording technologies are increasingly available through remote sensing from satellites and drones even though their use by individual farmers is still limited. Field sensors are increasingly being deployed in higher value crops such as orchards and vegetables but also in field crops, to support irrigation management and for early warning of diseases. Reacting technologies such as VRAs (Variable Rate Applications) are being adopted more slowly, as they are most complex requiring proper recording technologies as well as sufficient intra-field heterogeneity to be profitable for farmers. Evidence in Turkey suggests a similar pattern: As such, farmers are less convinced about their profitability and require more sensitization, training and support (Say et al. 2017).

Satellite technology has also shown significant progress for imaging applications among PA technologies. For example, remote sensing (RS) is used successfully to detect variability in soil and crop conditions and to match inputs such as water, seed, and fertilizer via variable rate technology. Currently, satellite imaging technology is more suitable for large areas due to its cost effectiveness in comparison to drone-based imaging. However, with a number of high-precision satellite launches being planned, that precision capabilities will improve significantly to enable usage for medium-sized and small fields.

Drone-based imaging in PA has evolved rapidly over the last few years. Current drone imaging favours usage of smaller farms where satellite imagery is not cost effective. With the improvements in satellite technology described above, however, drone-based imaging may be limited to certain conditions such as heavy cloud cover or difficult terrain. With regards to precision spraying, however, drones may prove to be a significant advantage as payload capacity continues to increase.

Lastly, farm management systems are another interesting and developing area in the PA ecosystem. They assist farmers and land managers in achieving higher yields and less waste through smarter resource management and greater reduction of input 
costs. Current farm management systems use predictive algorithms to issue warnings on imminent pest attacks and other key risks affecting farm productivity.

\subsection{Agriculture 4.0}

The agricultural sector sets sail towards a new era of agriculture called "Agriculture 4.0" thanks to emerging novel digital technologies. Agriculture 4.0 finds solution to agricultural and environmental problems thanks to digitalization, automation, and artificial intelligence adjusted to various agricultural technologies from crop and livestock production, to weeding, to pest control, and also to harvest.

Most studies related to new digital technologies are carried out on topics, such as Information and Communications Technologies (ICT), Internet of Things (IoT), Cloud Computing (CC) Big Data Analytics (BDA), robotics, Machine Learning (ML), Deep Learning (DL), Artificial Intelligence (AI), Unmanned Aerial Vehicles (UAVs), Unmanned Ground Vehicles (UGVs), and Blockchain. There are many literatures covering various applications used in Agriculture 4.0 in the past few years: ICT (Lezoche et al. 2020; Moysiadis et al. 2021); WSN (Ojha et al. 2015; Kochhar \& Kumar 2019), IoT (Sinha \& Dhanalakshmi 2022; Zhang et al. 2021; Sadowski \& Spachos. 2020; Lin et al. 2020; Tzounis et al. 2017; Ayaz et al. 2019; Kim et al. 2018; García et al. 2020; Kour \& Arora 2020; Marolia et al. 2021; Tao et al. 2021), Big Data (Newton et al. 2020; Lezoche et al. 2020; Moysiadis et al. 2021; Wolfert et al. 2017), UAV technology (Moysiadis et al. 2021; Kim et al. 2018; Boursianis et al. 2020), and Artificial Intelligence (Moysiadis et al. 2021; Jha et al. 2019), Machine Learning (Moysiadis et al. 2021; Liakos et al. 2018), Blockchain (Chen et al. 2020; Bera et al. 2022; GHD and AgThentic 2018), Automation \& Robotics (Aceto et al. 2019; Carolan 2019). Furthermore, other smart farming topics including 3D Printing, Synthetic Biology, Gene Editing, Nano Materials have been researched by GHD \& AgThentic (2018).

Nonetheless, Agriculture 4.0 paradigm occurs five core technologies covering sensors and robotics, Internet of Things, cloud computing, data analytics, decision support system. Figure 6 shows core technologies and connections among them. (1) Sensors and robotics fulfill sensing and actuating functions, according to the needs of the system. (2) IoT provides connectivity based on protocol and network for data communication. (3) Cloud computing is responsible for data storage and processing. (4) Data analytics involves big data and AI and ML-based algorithms for data analysis. (5) Decision support system helps to provide data visualization, guidance functions, and user interaction (Araújo et al. 2021).

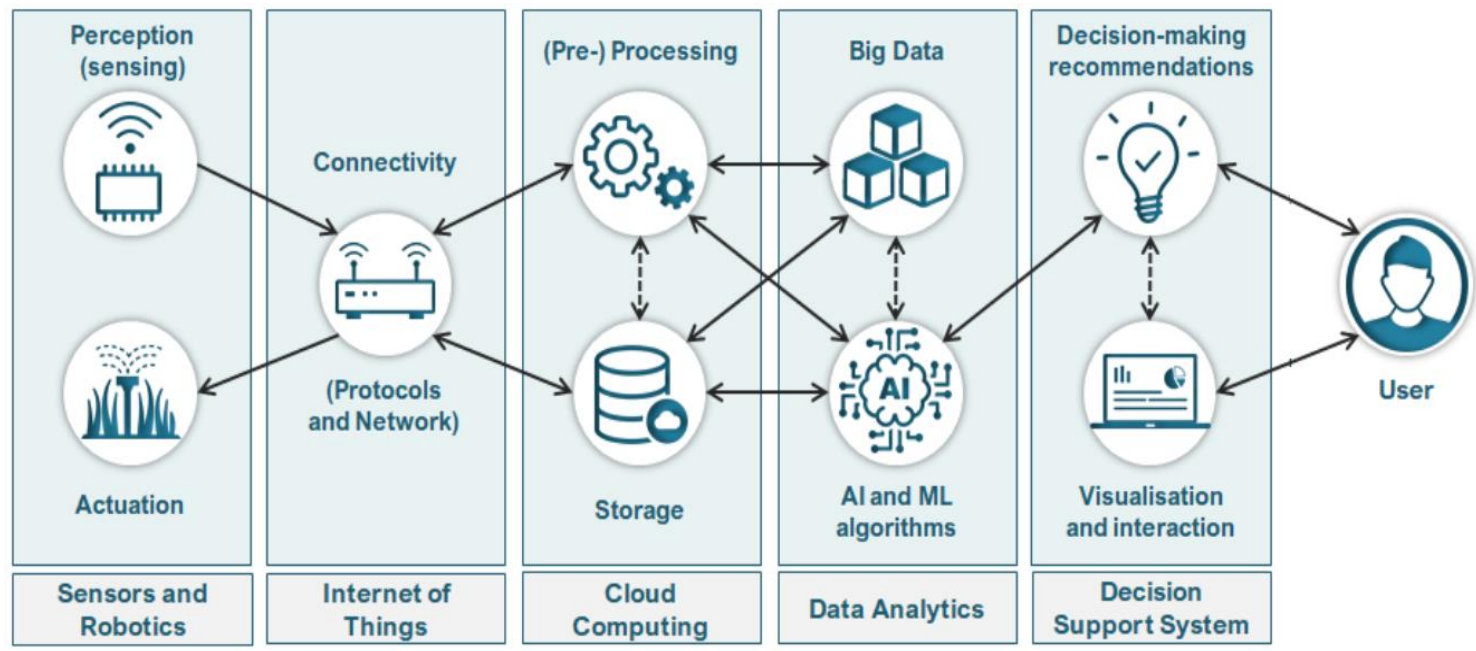

Figure 6- Agriculture 4.0 core technologies and connections (Araújo et al. 2021)

\subsubsection{Novel digital technologies}

Industry 4.0 has the potential to transform the production capabilities of whole industries, including the agricultural fields. Connectivity is the cornerstone of this transformation and IoT is a key enabling technology that is increasingly part of agricultural equipment. Technologies, such as IoT, Edge Computing, AI, robotics, 5G, blockchain, and supercomputing, all have the potential to make agriculture more efficient, sustainable, and competitive. Some definitions related to the advanced digital technologies given by European Commission are following (EC 2021a):

The Internet of Things (IoT) refers to the network of smart, interconnected devices and services that are capable of sensing or even listening to requests. IoT is an aggregation of endpoints that are uniquely identifiable and that communicate bidirectionally over a network using some form of automated connectivity. The IoT enables based on networked sensors to remotely connect, track and manage products, systems, and grids. 
Cloud computing includes the use of tools and applications such as data storage, servers, databases, and software based on a network of remote servers through the Internet. Cloud computing services enable users to store files and applications in a virtual place or the cloud and access all the data via the Internet. Public cloud services are available on public networks and open to a widely unlimited cosmos of potential users, designed for a market, not a single enterprise.

Big Data is a term describing the continuous increase in data, and the technologies needed to collect, store, manage and analyze it. It is a complex and multidimensional phenomenon, impacting people, processes, and technology. Big Data is usually characterized by "four Vs ": Volume (size of the data sets), Velocity (high speed of data processing), Variety (different types and sources of data used), and Veracity (high quality of analyzed data).

Artificial Intelligence (AI) is a term used to define machines achieving human-like cognitive functions such as learning, understanding, reasoning, or interacting. It comprises different forms of cognition and meaning understanding (e.g. Speech recognition, Natural Language processing) and human interaction (e.g. signal sensing, smart control, simulators). In terms of its technology base AI is a very heterogeneous field. While some aspects like sensors, chips, robots as well as certain applications like autonomous driving, logistics, or medical instruments refer to hardware components, a relevant part of AI is rooted in algorithms and software.

Agricultural robots can be used for crop monitoring and plant phenotyping, yield estimation, soil sampling, smart irrigation, smart spraying, dairy milking, sorting tasks, disease detection, weed and pest control, planting, harvesting, environmental monitoring and pruning. UAVs and UGVs are robots that are used both in the air and on land for agricultural applications.

Blockchain is a shared, digital, immutable ledger that facilitates the process of recording transactions and tracking assets in a business network. Shared ledgers technology allows new transactions to be added to an existing chain of transactions using a secure, digital or cryptographic signature. Assets can be tangible (house, car, cash, land) or intangible (intellectual property, patents, copyrights, brand). Blockchain protocols aggregate, validate, and relay transactions within the blockchain network. Almost anything of value can be tracked and transacted on a blockchain network, reducing risk and reducing all costs involved in the business. Blockchain is ideal for presenting information as it provides instantaneous, shared, and completely transparent information stored in a non-modifiable ledger that can only be accessed by authorized network members. A blockchain network can track orders, payments, accounts, production, and much more. As members share a single view of the truth, all the details of a transaction can be seen from start to finish; thus, creating new efficiencies and opportunities as well as greater confidence.

Industrial Biotechnology is the application domain of biotechnology for the industry in the production and processing of chemicals, materials, and fuels. This technology involves the practices related to using microorganisms or enzymes to generate industrially useful products in a more efficient way (e.g. less energy use, or fewer by-products) without conventional petrochemical processes.

Nanotechnology is an umbrella term that covers from the design to structural application and production, to devices, and systems by controlling shape and size at a nanometer scale. Nanotechnology has revolutionary the potential for the development of smart nano and micro-devices and systems in fields such as agriculture, healthcare, energy, environment, and manufacturing. Nanotechnology use in agriculture allows smart solutions for nutrients, pesticides, and genetic materials for improved soil fertility and soil protection, thanks to better stress tolerance. Nano-based sensors can be used for monitoring whole factors that affect productivity in smart farming. Moreover, nanotechnology can be used in post-harvest food processing and packaging to reduce food contamination and waste.

Photonics is a multidisciplinary field related to light including energy generation, detection, and process management, devices such as electronic components, and photodiodes, lasers, and LEDs. It allows the technological basis for the economic conversion of sunlight to electricity for solar-powered systems.

\subsubsection{Agriculture 4.0 applications}

Agriculture 4.0 can be applied at four main groups as showed in Figure 7: (a) monitoring; (b) control, (c) prediction, and (d) logistics (Araújo et al. 2021). 


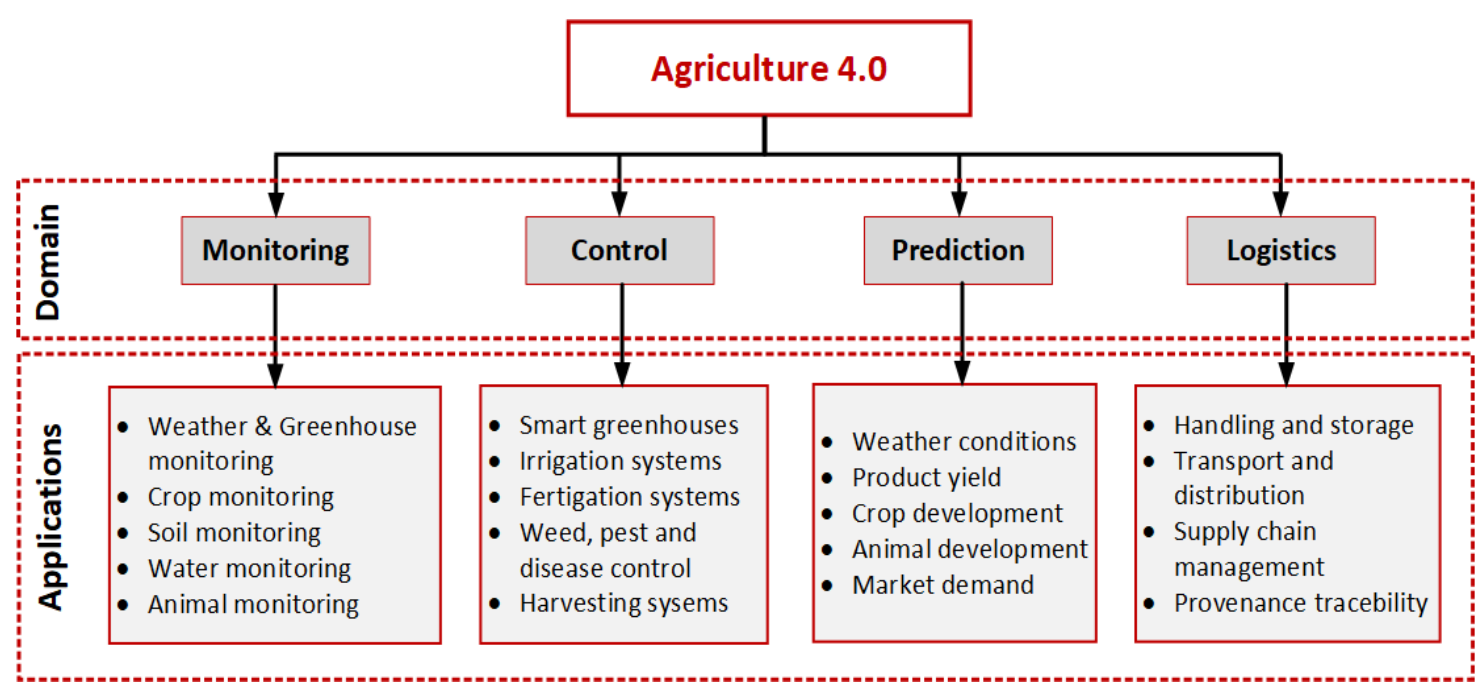

Figure 7- Domains and applications in Agriculture 4.0 (Araújo et al. 2021)

Monitoring- Automatic monitoring is the first step to passing to Agriculture 4.0. Smart monitoring systems have potential changing the game rule thanks to real-time data collected from the field and advanced data analytics tools providing the success of agricultural management. Monitoring allows farmers to get smart and fast decisions and perform timely interventions, to increase productivity in agriculture, save time and costs and protect the environment (Araújo et al. 2021).

Monitoring include usually applications as follows:

- Weather monitoring (air temperature and humidity, rainfall, wind direction, wind velocity, atmospheric pressure, solar radiation, etc.).

- GHG monitoring (temperature, $\mathrm{GHG}$ emissions- $\mathrm{CO}_{2}, \mathrm{CH}_{4}, \mathrm{~N}_{2} \mathrm{O}, \mathrm{SO}_{2}$ ).

- Crop monitoring (NDVI) and soil monitoring (temperature, moisture, electrical conductivity, $\mathrm{pH}$ value, and nutrient content) for agricultural management.

- Water monitoring (temperature, conductivity, $\mathrm{pH}$, salinity, turbidity, specific chemical compounds, dissolved oxygen content) for irrigation systems, aquaculture or aquaponics (aquaculture + hydroponics) for management.

Control- While information is managed in one way in the monitoring applications, the control applications use a bidirectional information line. Commonly, an IoT-control system works together automatic monitoring system, which employs IoT sensors to collect necessary data and to transfer them for storage and then processing. Control applications are the following (Araújo et al. 2021):

- Irrigation Systems (sensors, actuators such as water pumps, and solenoid valves) for irrigation management.

- Fertilization and Fertigation for optimum fertilization.

- Weed, Pest and Disease Control for many problems like a waste of chemicals, increased costs, and pest resistance to chemicals, environmental pollution, and contamination of agricultural products.

Prediction- Predicting function in Agriculture 4.0 is used in decision-making support for the optimization in the management process. Monitoring and documentation are vital processes since it is used real-time and historical data to improve exact analytical methods in predicting actual events. Prediction applications are the following (Araújo et al. 2021):

- Forecasting Weather Conditions

- Crop Development and Yield Estimation

- Forecasting Market Demand

Logistics- It is known that, in recent years, consumers have been more concerned about how the agri-food products bought are produced, handled, packaged, stored, and distributed. Agriculture 4.0 provides more efficient management and transparency by increasing efficiency in logistics, addressing food safety and security, traceability and food authentication, decreasing intrinsic risks, and complying with certifications and regulations (Araújo et al. 2021). 


\subsubsection{Examples from digital agriculture}

Several application examples related to domains such as monitoring, control, prediction, and logistics of smart farming are given below.

Smart Livestock Farming (SLF) is one of applications of PA that supports real-time monitoring of productions, health, and welfare of livestock, and to ensure optimal yield, to increase the management capacity of animals. A variety of sensors and actuators and decision-making tools, and IoT technologies are used in SLF (Cadero et al. 2018). Electronic identification systems such as ear tags, ruminal boluses, and sub-cutaneous radio-frequency identification; on-animal sensors like accelerometers, global positioning systems, and social activity loggers; and stationary management systems, milking parlor, and related technologies and flock management software are used in SLF (Vaintrub et al. 2021). Newton et al. (2020) examined a case study related to the dairy milk recording system under Australian conditions, using big data analytics based on individual cow and herd performance information, such as milk production, lactation, and breeding records. They studied farm decision support using big data and explored various factors and processes along with farmer engagement. Knight (2020) reviewed the current status of wearable sensor technologies in livestock farming that could revolutionize dairy farming; explained the important difficulties, and emphasized the advantages need for animal wellbeing, profitability. Sensors are split into three categories: (1) "At Cow" sensors, (2) "Near Cow" sensors, and (3) "From Cow" sensors. Wearable sensors can be placed by swallowing or inserting into cows. Figure 8 shows wearable sensor technologies developed for cows. While "At Cow" sensors at the red zone are used to measure acceleration, temperature, heart rate, and $\mathrm{pH}$, "Near Cow" sensors at the blue zone are used to analyze video and sound information, as well as climate analysis, feed analysis, and GPS, these are designed to be make interaction with the cloud. "From Cow" sensors at the green zone are employed to monitor products and wastes like milk, hair, saliva, sweat, nasal secretion, breath, and faeces taken from the cow. Zhang et al. (2021) pointed out that SLF has important potential thanks to intelligent technologies such as environmental control, disease early warning, precise feeding, and remote diagnosis. They discussed the framework and technical characteristics of wearable Internet of Things (W-IoT), the advantages, difficulties, and expectations of the W-IoT in farm animals (Figure 9).

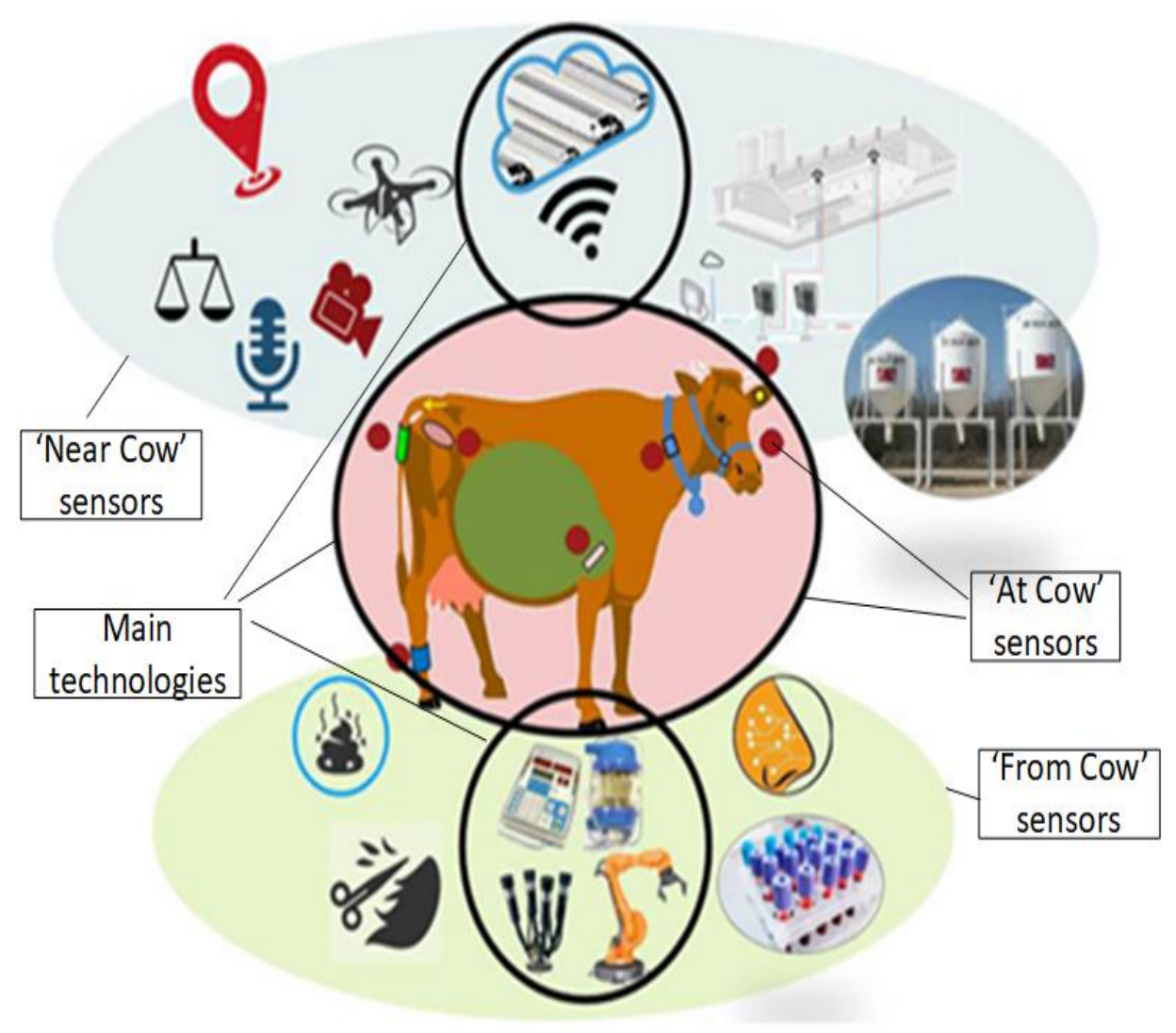

Figure 8- Overview of sensor technologies associated with dairy animals for cows (modified from Knight 2020) 


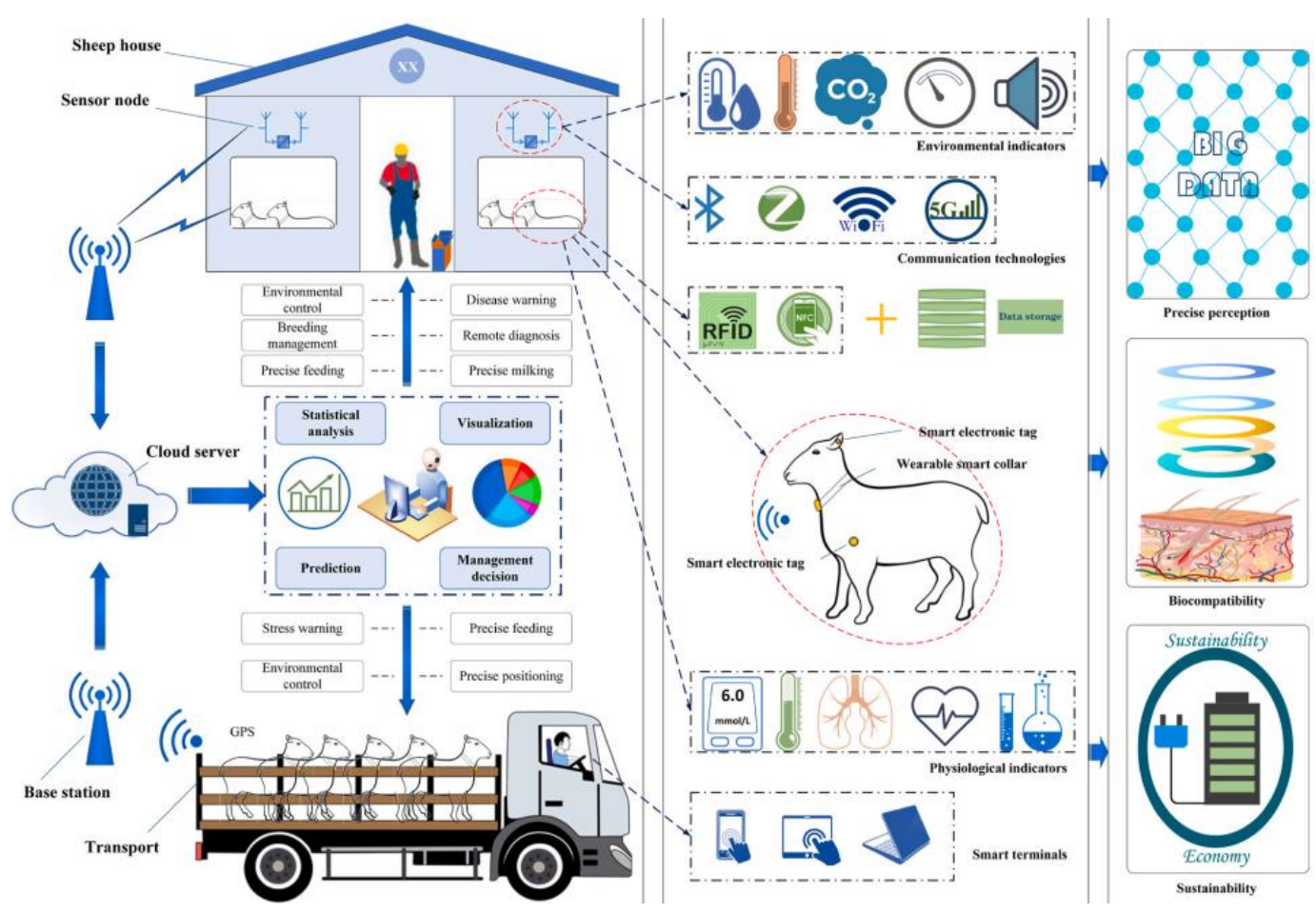

Figure 9- Wearable IoT system for SLF (Zhang et al. 2021)

Smart greenhouses enable farmers to cultivate crops with minimum human interference. Climatic conditions such as temperature, humidity, luminosity, and soil moisture are continuously monitored inside a greenhouse. Variations in these conditions will trigger automated actions. These actions will then evaluate the changes and implement corrective actions to maintain optimal conditions for plant growth.

Zamora-Izquierdo et al. (2019) proposed a flexible platform for greenhouses that used soilless culture with full recirculation. The system that obtained saving of more than $30 \%$ in water consumption and up to $80 \%$ in some nutrients has low-cost hardware and a three-tier open-source software platform at local, edge, and cloud planes.

Liao et al. (2017) developed an IoT-based system including three subsystems like environmental monitoring system, a wireless imaging platform, and a host analysis platform, shown in Figure 10. In an orchid greenhouse, environmental sensors that measure temperature, relative humidity, and illumination, and cameras capture the images of orchids were used. The IoTbased environmental monitoring system consists of $12 \mathrm{WSN}$, and a gateway based on ZigBee. While WSNs are responsible for measuring environmental parameters, the gateway is used to organize the sensor readings sent by the WSNs and transmit them to the host via Wi-Fi. The IoT-based wireless imaging platform is built upon a Raspberry Pi single-board computer with cameras. Sensor data and camera images are saved in the host platform.

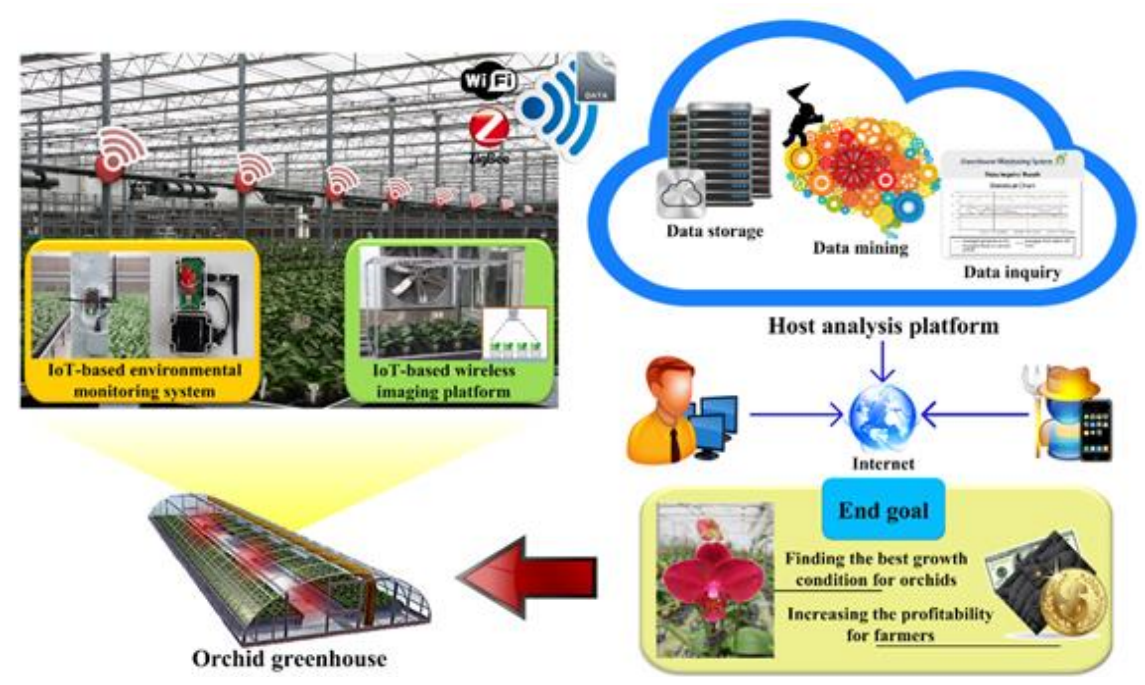

Figure 10- Overall conceptual diagram of IoT-based monitoring system for greenhouses (Liao et al. 2017) 
Lin et al. (2020) developed a framework using a linear programming model maximizing economic profits and environmental benefits for the IoT-based irrigation and fertilization system in which both long-term and short-term planning are considered as illustrated in Figure 11.

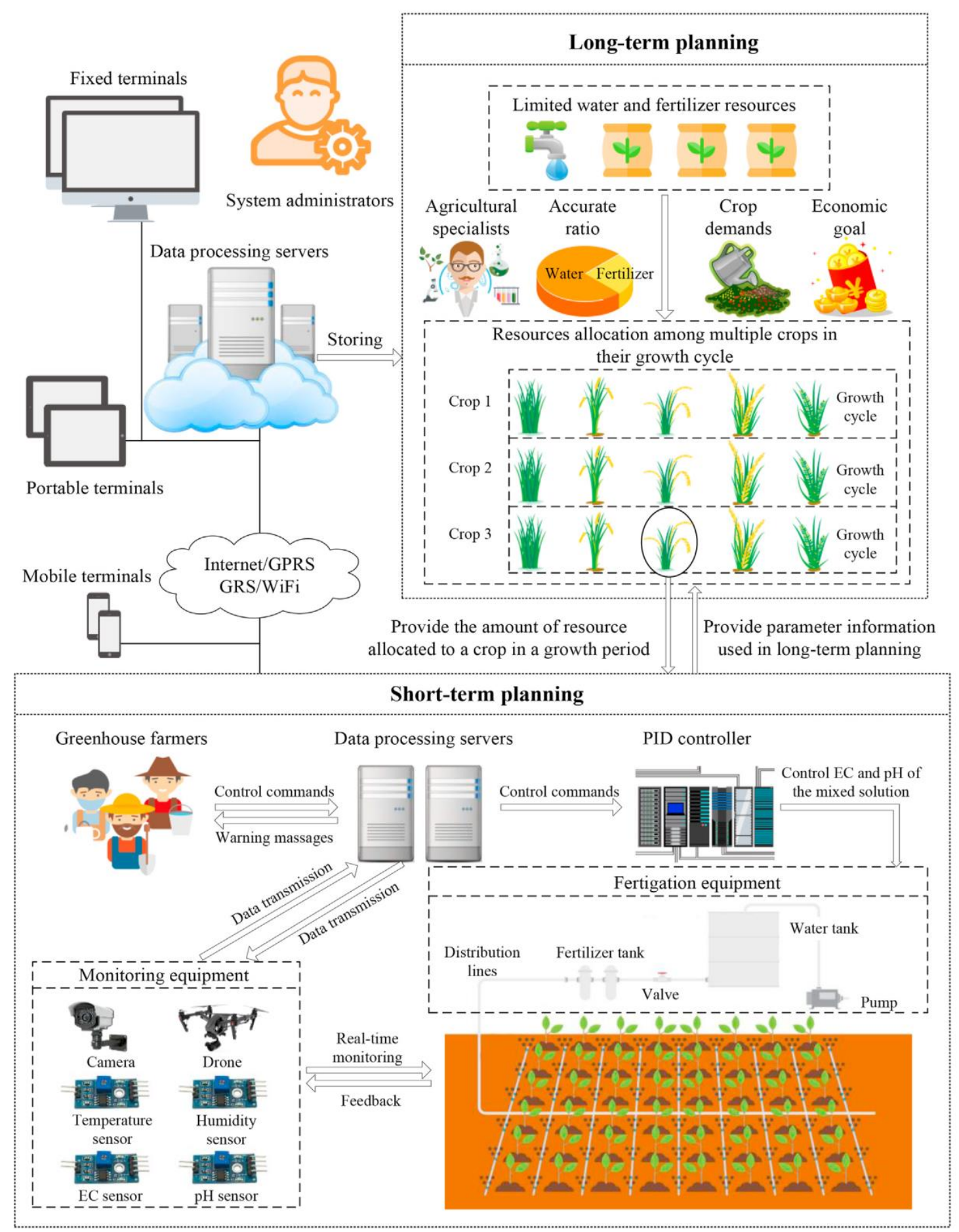

Figure 11- IoT-based smart fertigation management system (Lin et al. 2020)

Roy et al. (2021) designed an IoT system according to a dynamic irrigation scheduling called "AgriSens" for efficient water management of irrigated crop fields. The AgriSens enables real-time, automatic irrigation, as well as remote manual irrigation for different growth phases. IoT helps not only enhance the efficiency of irrigation processes but also minimize water losses. In order to calculate the precise needs for water, sensors that measure various parameters, such as relative humidity, soil moisture, temperature, and light intensity, need. IoT-based smart irrigation systems with such a mechanism can contribute to higher irrigation efficiency. Benyezza et al. (2021) proposed a block diagram of the example irrigation system, which is composed of three main parts, as shown in Figure 12: data processing, cloud, and communication part. 


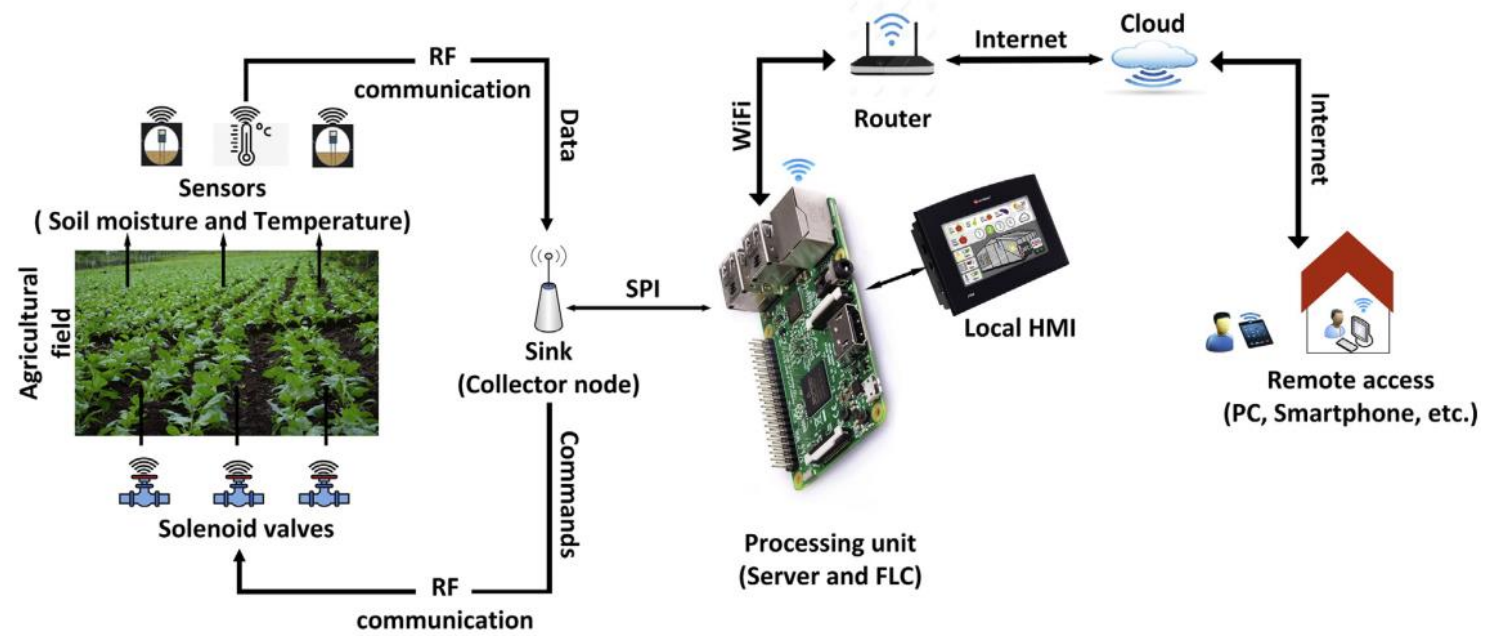

Figure 12- Block diagram of the example irrigation system (Benyezza et al. 2021)

Chen et al. (2020) proposed a framework called "blockchain-based electronic agriculture" on its development and challenges of Ecological Farm in the Beijing Liuminying. According to this framework, the whole circular agricultural model of the ecological farm into the blockchain network automatically handles and uploads data through several types of smart devices, which expands the information set that can be used for sharing. This innovation provides a powerful agriculture model, and presents a reliable path for reaching "digital agricultural". As shown in Figure 13, Blockchain-based applications can be used along with IoT smart devices and drones to monitor agricultural environments (Bera et al. 2022).

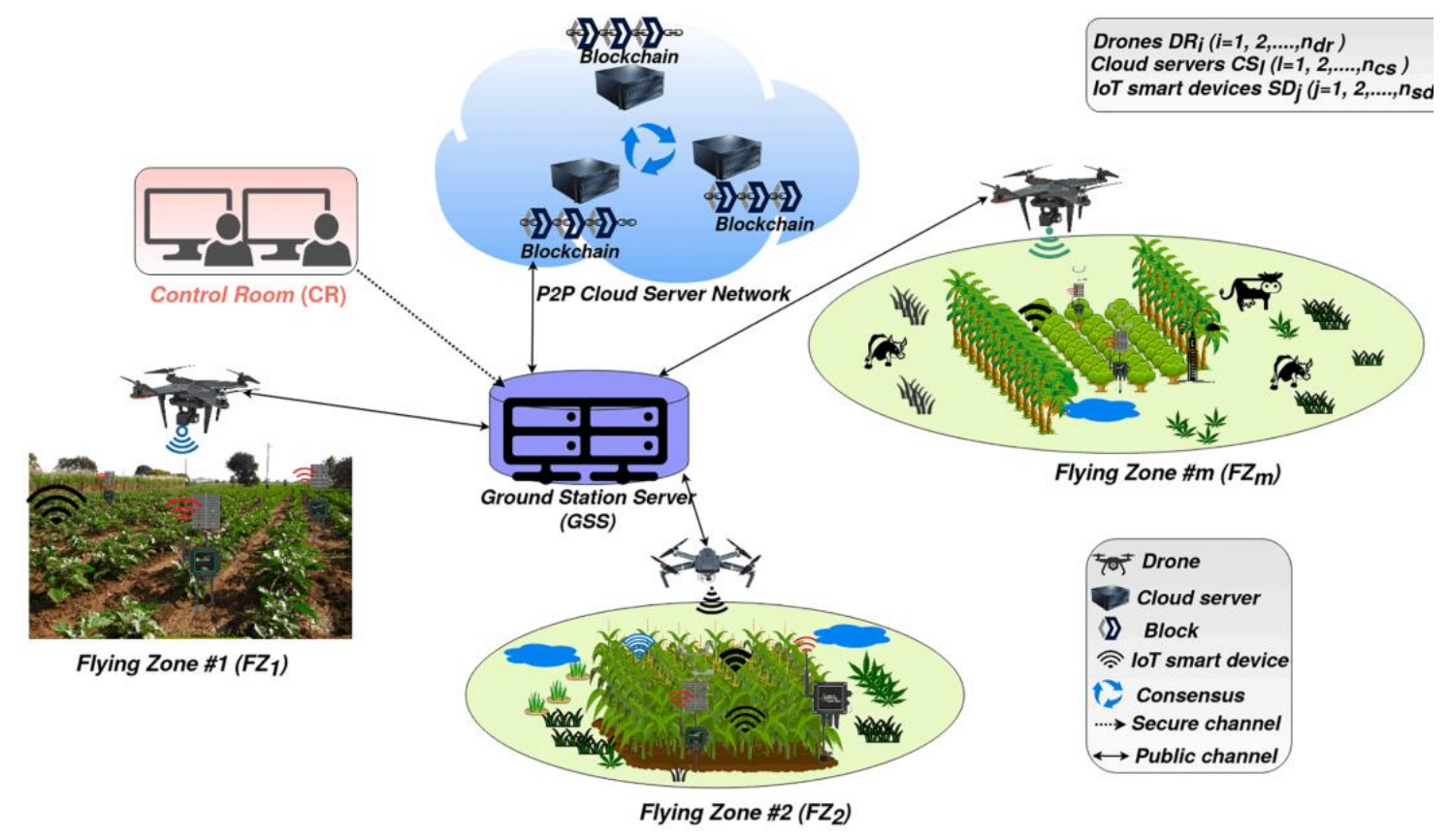

Figure 13- Blockchain-IoT enabled agriculture using drones (Bera et al. 2022)

The European Commission has set up large-scale projects to initiate the digitization of agriculture in Europe with approximately $€ 1$ billion of EU funding under the Horizon 2020 program (EC 2021b). Several examples of these projects are given below:

ATLAS project is agricultural interoperability \& analysis system, also being an open digital service platform for agricultural applications. The goal of ATLAS is the development of an open interoperability network for agricultural applications and to build up a sustainable ecosystem for innovative data-driven agriculture. The platform enables the flexible combination of agricultural machinery, sensor systems, and data analysis tools to overcome the lack of interoperability. This allows farmers to increase their productivity in a sustainable way. The ATLAS platform is built around a data exchange network using a uniform application program interface (ATLAS 2019). 
IoF2020 investigates the potential of the IoT technologies in the European food and farming industry both precision farming and smart farming (IoF2020 2017). IoT-driven smart farming enables farmers to optimize their operating tasks to boost crop yields and to reduce the costs of inputs such as water, fertilizer, insecticides, and herbicides.

DEMETER project is a large-scale deployment of farmer-driven, interoperable smart farming-IoT based platforms, delivered through a series of 20 pilots across 18 countries (15 EU countries). Involving 60 partners, DEMETER adopts a multi-actor approach across the value chain (demand and supply), with 25 deployment sites, 6000 farmers and over 38000 devices and sensors being deployed (DEMETER 2019).

Some of EU's robotics projects are Vinbot, MARS, GRAPE, VINEROBOT, ROMI and Flourish projects (Moysiadis et al. 2021). Vinbot aimed operations crop monitoring using devices like laser sensors, cameras and the navigation system that is based on a hybrid reactive/GPS (VINBOT 2017). MARS subproject was designed for the development of a mobile agricultural robot, which had the ability to cooperate and work in swarms (Figure 14a). GRAPE subproject targeted to develop a UGV able to perform semi-autonomous vineyard monitoring and farming tasks (Figure 14b). VINEROBOT aimed to develop a novel UGV capable of monitoring grape growth and factors like grape yield, vegetative growth, water stress, and grape composition in covering vineyard management (Figure 14c). ROMI project is developed for a UGV performing tasks such as weeding, crop monitoring, and collecting specific information on any individual plant (ROMI 2020). Flourish project is developed for weed control with UGV robots shown in Figure in 14d using data taken from UAVs (Flourish 2018).
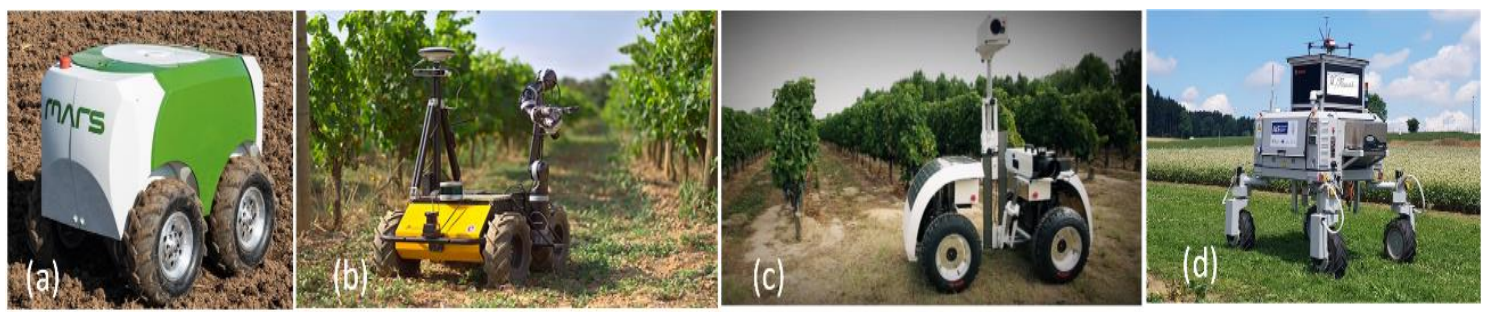

Figure 14- EU's robotics projects (a) MARS, (b) GRAPE, (c) VINEROBOT and (d) Flourish (Moysiadis et al. 2021)

\subsubsection{Digital transition and challenges}

Although the many gains that the success of Agriculture 4.0 could lead, there are still various challenges that need to be handled for providing a successful digital transformation. The main challenges to be considered in Agriculture 4.0 are split into five main levels. Those challenges are related to device, data, network, application, and the system according to levels. Challenges at device levels are usually related to a harsh field environment, power consumption, and cost issues. Data levels are mostly linked to quality, availability, privacy, integrity, and interpretability issues. Facing at network levels are mostly network size, latency and throughput, transmission range, propagation losses, and interoperability issues. Emerging of during applications are usually realtime use, context-awareness, cyber-security, modularity, and reliability problems. Problems that emerged in the system are scalability, flexibility, robustness, complexity, affordability, and continuous improvement issues (Araújo et al. 2021).

As noted earlier (besides the small scale of land and low level of mechanization), farmers face significant challenges in the transition to smart farming as they try to adopt sensors, biologicals, robotic automation, and digital data from third-party providers. Farmers are traditionally conservative and adopt new technology solely for its usefulness rather than its technological appeal. As a result, compelling applications must be significantly deep to deal with the farmer's specific situation, while also relying on integrated solutions that make data and insights easy and seamless.

There are two basic stages in smart farming that should be taken into account for the transition: (1) The pre-processing stage and (2) the post-processing stage. The pre-processing phase covers market trends geographical conditions and soil properties of the land, seeds choosing, and the land preparation for the smart farming system. The post-processing stage is employed machine vision techniques for disease and weed identification while using smart technologies in irrigation and harvesting. For traditional agricultural players, this transition is not easy. As the industry moves from products to outcome-based solutions and worksite optimization, many organizations face the conflict of traditional platform or product-based organizations versus the needs of the farmer and marketplace. As a result, smart farming is undergoing a rapid transformation from both a product and a service perspective. Technological disruptions, business model transformations, and organizational changes are all creating an exciting but challenging opportunity.

\section{Renewable Energy and Environmental Technologies}

Renewable energy technologies have the potential to provide synergy between water, energy, and food; and also, the optimum mix is available for three sectors. Solar-based pumping solutions offer a cost-effective alternative to the grid- or diesel-based irrigation pumps. Renewable energy and rainwater harvesting technologies can be combined with a nexus system. Renewable 
energy technologies such as solar energy, wind energy, and bioenergy can be integrated into agriculture in villages and cities. If coupling an energy storage system with renewable energy technologies, the excess energy generated can be stored to use in the future. As an alternative solution to the Nexus approach, new applications where photovoltaic panels are combined can be used in field and horticulture, and aquaculture.

\subsection{Agrivoltaics}

Agrivoltaic systems are PV technologies installed at a certain height from the ground, making it together integrating agriculture and solar energy. Agrivoltaic systems can provide both preserve agricultural land and advantage crop production by increasing water use efficiency and decreasing water stress (Agostini et al. 2021; Allardyce et al. 2017). Sun'Agri agrivoltaic system driven by artificial intelligence in Piolenc provides the vines shaded by the pivoting solar panels continue to grow and show a reduced need for water thanks to the reduction in evapotranspiration (pv magazine 2020). However, these positive attributes need comprehensive environmental and economic analysis of agrivoltaic systems. Figure 15 shows various applications of agrivoltaic systems.
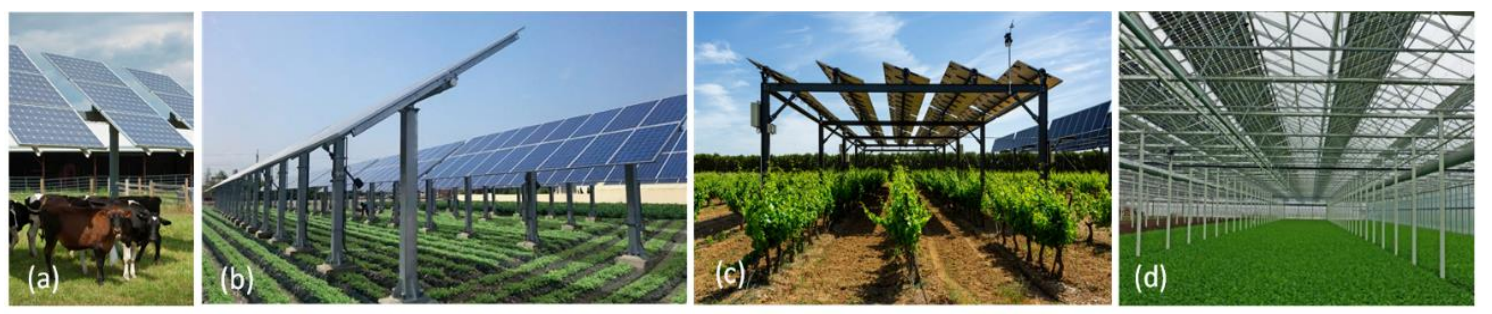

Figure 15- Agrivoltaic systems: (a, b) Agrovoltaics a solar innovation and triple usage of solar energy (Agrovoltaics 2021), (c) Sun'Agri's agrivoltaic experiment in Piolenc, France built on vineyards (pv magazine 2020), (d) Agrivoltaics on a greenhouse roof. Swissradies Kerzers, Switzerland (Allardyce et al. 2017)

\subsection{Aquavoltaics}

Aquavoltaics (AquaPV) is a concept emerged with combining electricity production and aquaculture. AquaPVs floating on the water body can lessen water losses preventing evaporation by up to $70-85 \%$ due to covering the water. The aquavoltaics technology enables electricity to be generated and aquaculture to be carried out in the same area, and thus significantly improves overall productivity per unit area compared to conventional land use. Several projects and studies are carried out to verify positive and negative aspects in terms of ecosystem and the technical and economic feasibility of dual-use in Aquavoltaics (Pringle et al. 2017, Fraunhofer 2021; Solaripedia 2021; PV TECH 2021). Figure 16 shows various applications related to aquavoltaic and floatvoltaic systems.
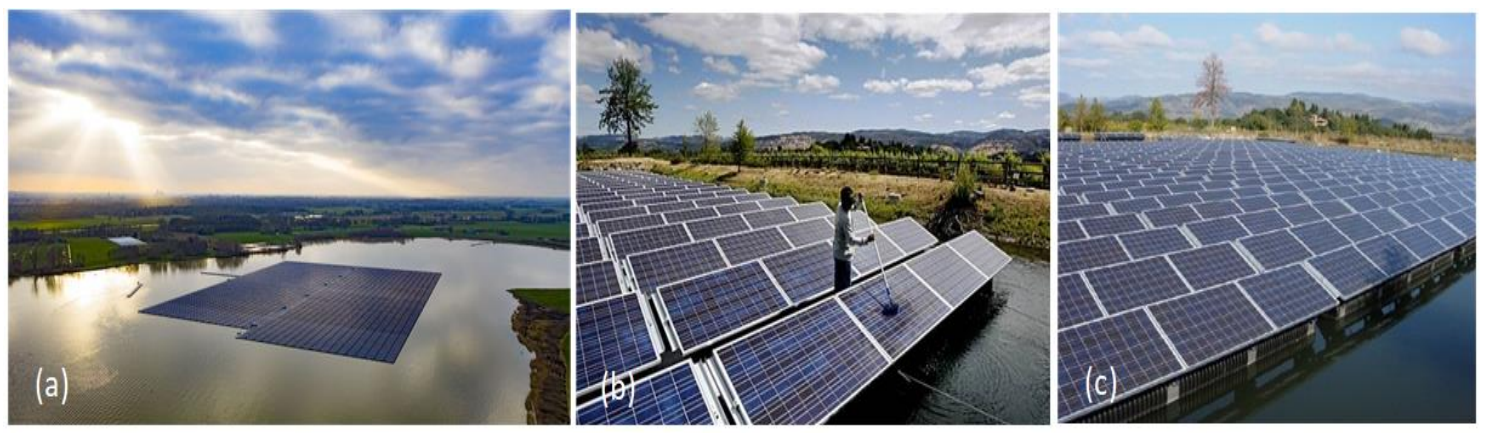

Figure 16- Aquavoltaic systems: (a) Floating PV plant on Dutch lake (PV TECH 2020), (b) Floating solar power system located in California's Napa Valley region (Solaripedia 2021), (c) India's largest floating solar plant (pv magazine 2021)

\subsection{Solar-powered monitoring system}

Industrial development including agriculture has caused pollution of natural resources such as water, air, soil, food. GHG emissions, heavy metals, pesticides, and other chemicals that pollute terrestrial and aquatic ecosystems pose, and also unbalanced water use in all sectors a threat to the health of animals and humans, so our future.

A nexus approach based on water-energy-food given in this study supports the transition to a green economy to solve whole those problems. The agricultural nexus planning combined with digital technologies can be used to solve challenges related to water, energy, and food including the environment. In this context, topics including overall agricultural management can be handled for the environment (water, soil, air - whole ecosystem), optimum water use, and efficient energy use. 


\subsubsection{Crop and soil monitoring}

Crop cultivation and any form of life on earth are inevitably dependent on sunlight, and today, thanks to modern technologies emerging, Sun offers a bigger source with the possibility to harness the energy from it all around the year. Not only does the development of the crop with energy coming from the sun but supports the gathering of precious information about the soil, air, water, and weather conditions themselves.

Solar-powered plug-and-play wireless field sensors provide farmers with instant access to data on their soil properties and crop health. This hardware is a device IoT-based, low-power, long-range, and adaptable based on farm size. A farm monitoring system shown in Figure 17 is a network of smart sensors driven by powerful AI-based crop intelligence and farm management software to aid farmers across the globe with instant access to soil and crop health. It is designed to help farmers accomplish high crop productivity and high-profit margins (Solarvibes 2021).

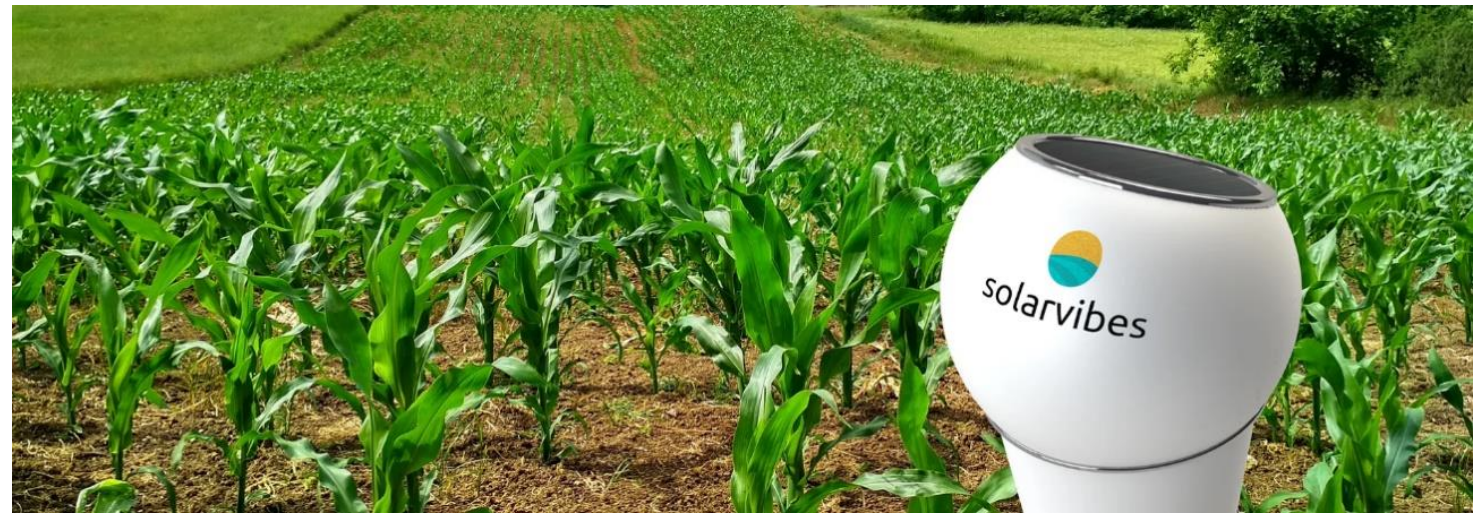

Figure 17- Solar-powered Plug \& Play Farm Monitoring System (Solarvibes 2021)

\subsubsection{Environmental monitoring}

Climate change is due to emissions of greenhouse gases (GHGs) that have been greatly affecting agricultural production. The side effects of climate change result in frequent experiences of droughts, floods, and extreme weather conditions. Data-driven IoT systems are have monitoring and control functions including reducing energy and fuel consumption, generating renewable energy on-site, and performing closed-loop measurements of carbon consumption and waste. It is seen that IoT-powered smart services and industry could account for up to 10 percent carbon reduction by increasing efficiency and eliminating reliance on disposable materials in both the public and private sectors.

Monitoring systems can assist farmers in monitoring and improving the quality to avoid degradation of soil. They allow for the monitoring of a number of physical, chemical, and biological properties such as texture, water-holding capacity, and absorption rate. Soil monitoring can help to minimize problems, such as erosion, densification, salinization, acidification, and pollution due to toxic elements (Yurtseven et al. 2018).

Pesticides and several other agrochemicals are used widely in agriculture. These chemicals that affect in way serious and permanent ecological balance are harmful to human and animal welfare, causing substantial damage to complete ecosystems. IoT-based smart devices, such as WSNs, drones, robots, enable farmers to substantially decrease the use of pesticides. Advanced IoT-based pests and insect control allow precise tracking, simulation, disease prediction, and therefore is more efficient than traditional pest control calendars or prescripts (Raj et al. 2021). The IoT-based systems with ML, DL, and image processing can be used in preventing fruit diseases, diagnosing and preventing infection in agricultural products. Studies have seen that chemical pollution can prevent using big data, AI, ML technologies. Wastewater from industry can be used in agricultural production; Water polluted with heavy metals threatens our food (paddy, greenhouse cultivation, fish production, etc.) and our health. In recent years, it is known that cancer and many diseases that adversely affect the immune system are caused by excessive agricultural spraying and industrial wastewater. Excessive use of pesticides in fields, vineyards, gardens, and greenhouses pollutes air, soil, and water resources. In other words, excessive spraying, irrigation, fertilization harm the entire ecosystem in an unsustainable way. All of this should be traced back to the source where the problem started; all data should be forwarded to the center and evaluated; monitoring and control mechanisms should be developed.

PA has not only the potential to reduce greenhouse gas emissions but also having a positive effect on-farm productivity and the economy. These technologies cover whole farming applications such as variable-rate spraying, irrigation planting, fertilization, and weeding (Balofoutis et al. 2017). Both driver assistance (Machine Guidance) and Variable Rate Technologies (VRT) contribute to climate change mitigation by reducing fuel and input use at given yields. Based on a literature review, the EU classifies GHG reduction potential of different Precision Agricultural Technologies (PATs) as it follows (Table 1): 
Table 1- Greenhouse Gas (GHG) reduction potential of different PATs (Balofoutis et al. 2017; EC 2019)

\begin{tabular}{ll}
\hline PAT & GHG reduction potential \\
\hline Nutrient application (VRT) & 5 \\
Irrigation (VRT) & 3 \\
Controlled Traffic Farming & 2 \\
Machine Guidance & 2 \\
Pesticide Application (VRT) & 2 \\
Planting/Seeding (VRT) & 1 \\
Weeding (Precision physical) & 1 \\
\hline
\end{tabular}

Variable-rate nutrient application has the highest GHG emission reduction potential amongst PA technologies, as nitrogen fertilizer is the main source of $\mathrm{N}_{2} \mathrm{O}$ that is the most influential GHG emitted from farming activities. Its impact on global warming is 298 times higher than that of $\mathrm{CO}_{2}$ (Soto et al. 2019). Variable-rate irrigation has a dual impact. (1) decreasing the energy need for water pumping from the water source, (2) reducing of the GHG emissions by applying the optimum irrigation scheduling. On the other hand, applications such as controlled traffic in agriculture, machine guidance, VRT-pesticide use have GHG reduction potential. Moreover, all-natural resources (water, air, soil) have threatened due to chemical contaminants, overwatering, over-spraying, over-fertilizing.

\subsubsection{Water monitoring}

Water Quality Index (WQI) that developed to measure water quality is determined through different water quality parameters, such as $\mathrm{pH}$, turbidity, temperature, chloride, electrical conductivity (EC), dissolved oxygen (DO), biological oxygen demand (BOD), and chemical oxygen demand (COD), etc. (Ahmed et al. 2020). Smart water management requires the integration of systems and a complex of measures to monitor, control and regulate the usage and quality of water resources as well as maintain the associated equipment (sensors, actuators, pipes, pumps, etc.). Smart water systems based on the combination of the IoT, big data, and AI technologies can help stop water scarcity from happening and remove the damage the incautious usage of water resources has already caused.

In rural areas shown in Figure 18, solar-powered wireless air - water - soil monitoring stations can be used to monitor environmental variables at vineyards, orchards, fields, fish farms, greenhouses, basis on the energy - food - water nexus at realtime.
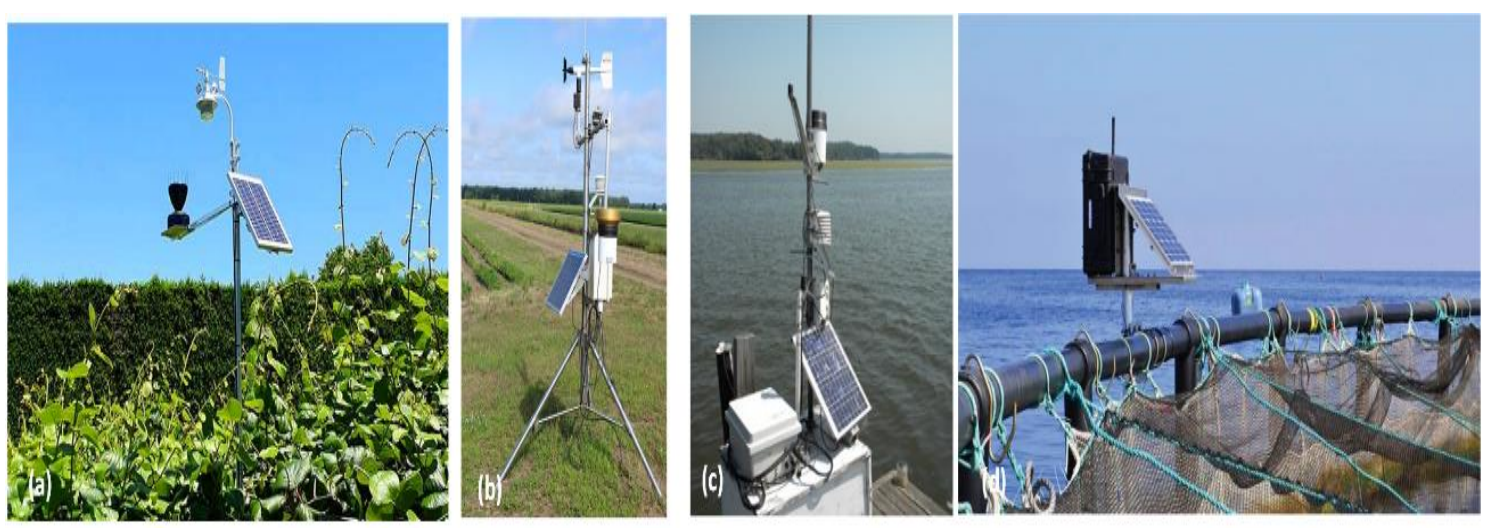

Figure 18- Solar-powered wireless-weather-soil-water stations (a) vineyard-orchard, (b) arable field, (c) water source, (d) aquaculture monitoring

\subsection{Solar-powered pivot irrigation system}

In a desert in Africa, a large pivot system with a radius of 479 meters has used to irrigate 50 hectares of desert. The fuel costs of operating this system are very high. Water is being supplied through an artificial canal from the Nile. At this point, Alfalfa is grown as feeding hay and harvested 11 times each year with the harvest season exceeding 300 days. Until 2013, a 135-kW diesel generator ran 22 hours per day to power the system. An alternative power source had to be found in this off-grid. Following feasibility analysis, a solar-powered system, using suitable pumps to replace the diesel-powered generator and AC pumps were installed. While all motors required to move the pivot now are powered with solar energy, the pivot speed is automatically controlled proportional to water flow. Figure 19 shows solar-powered center pivot irrigation system that is installed by Lorentz. In 11 hours, the pivot completes one 360 degrees turn, providing the required $3300 \mathrm{~m}^{3}$ of water per day for partial irrigation (Lorentz 2014). This energy transformation not only no longer decreasing energy costs, but also greatly reducing carbon emissions. 


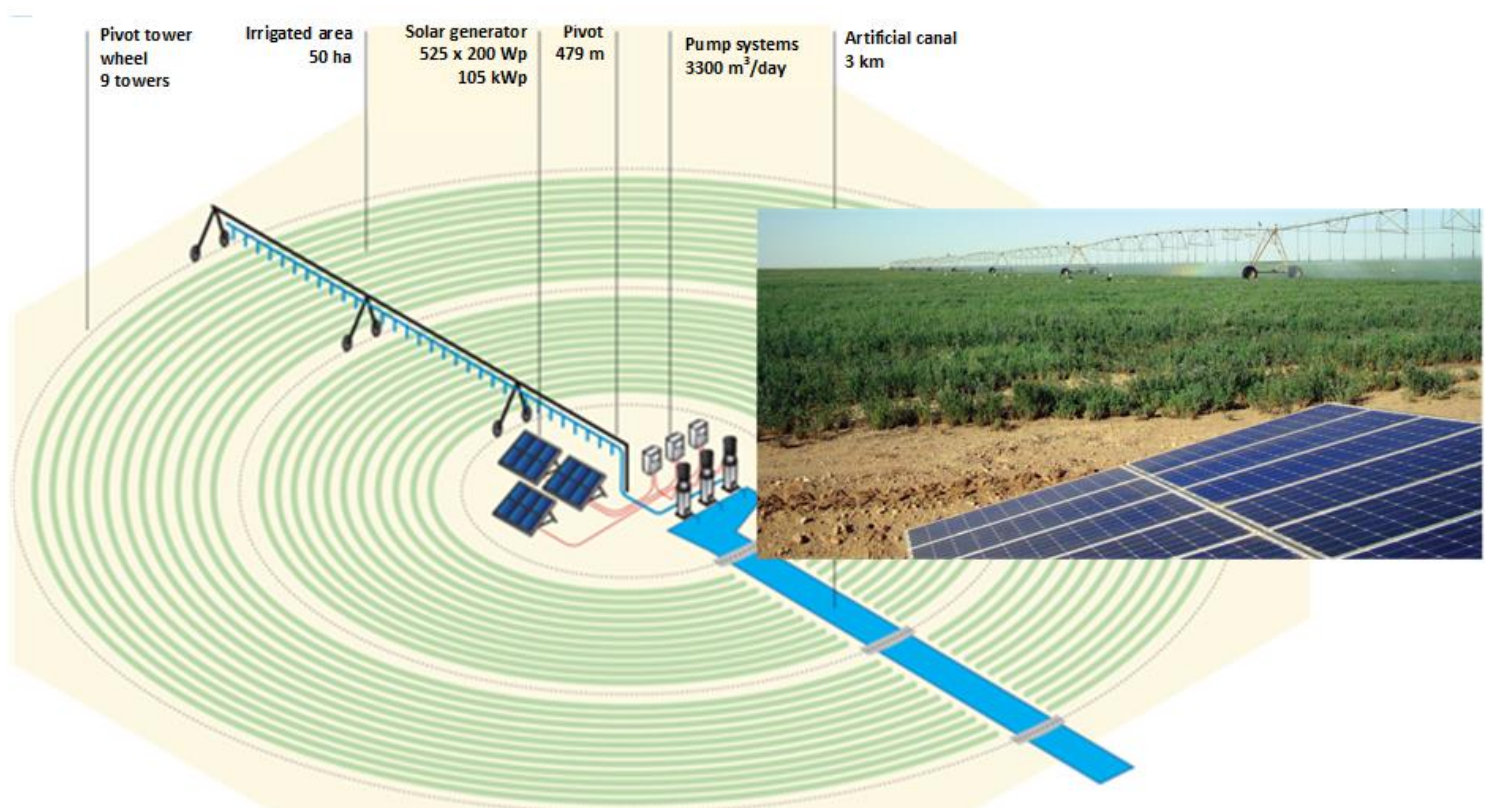

Figure 19- Solar water pumping for center pivot irrigation (Lorentz 2014)

\subsection{Solar-powered drip irrigation system}

In a valley in Chile, a drip system has used to irrigate 30 ha of vines planned like shown in the Figure 20 . The $2.5 \mathrm{~km}$ pipeline with diameter of $140 \mathrm{~mm}$, from the water source to two reservoirs, one of which is $40000 \mathrm{~m}^{3}$ and the other is $15000 \mathrm{~m}^{3}$, which is at 61 meters high was lay pipe. Submersible solar pump system was chosen being capable of delivering flows of up to 62 cubic meters per hour and to be operate at a maximum head of 90 meters. Power supply was provided with $16.56 \mathrm{~kW}_{\mathrm{p}}$ of photovoltaic modules installed on 6 tracked arrays. System design performance is taken as volume pumped $134000 \mathrm{~m}^{3}$ peak flow rate per year, $500 \mathrm{~m}^{3}$ per day, so with an annual average of $10 \mathrm{~L} / \mathrm{s}$.

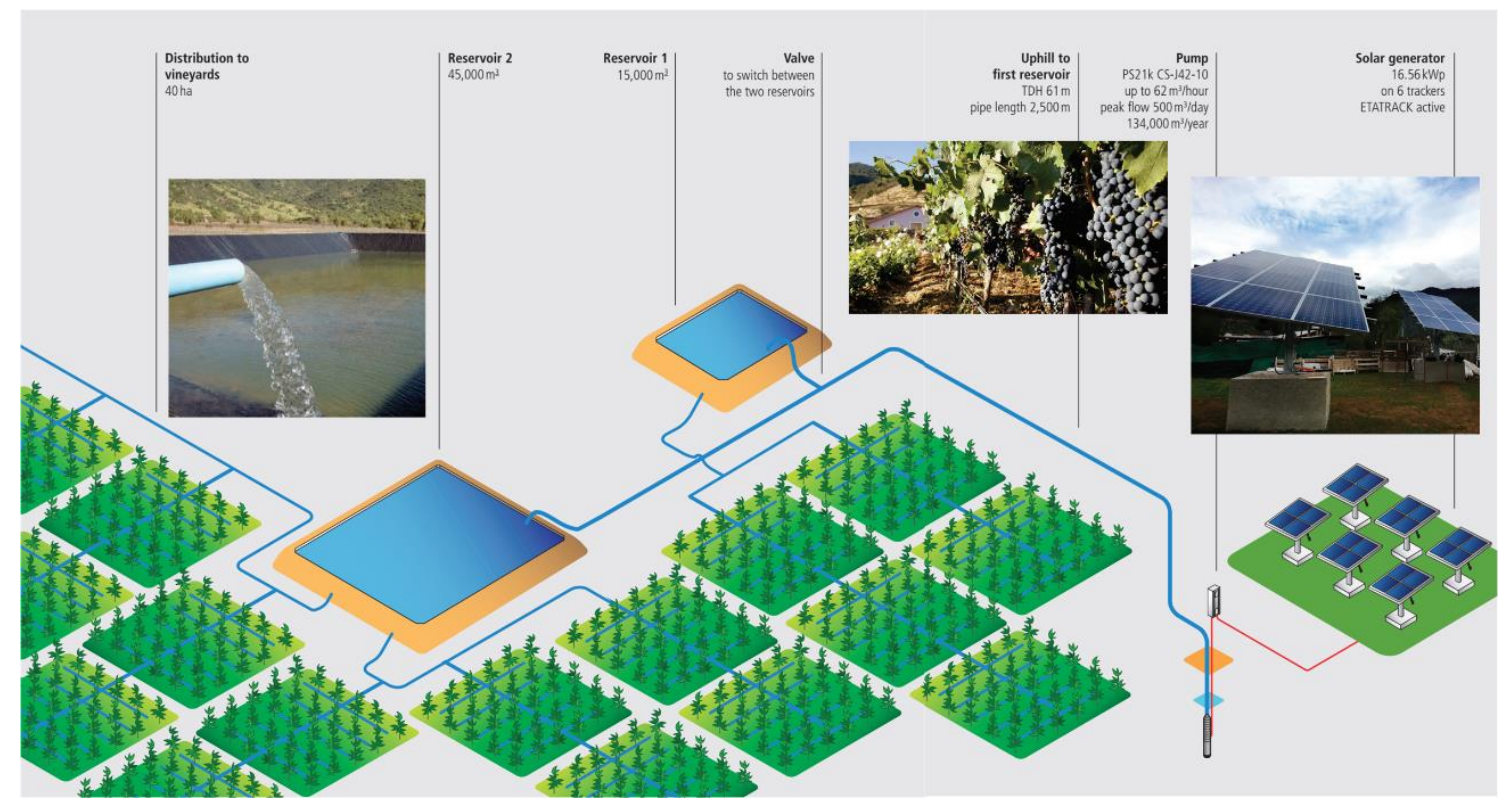

Figure 20- Solar-powered vineyard irrigation system (Lorentz 2012)

\subsection{Integrated Food Energy Systems (IFES)}

Food security and sustainable agriculture are the two main objectives of agriculture production process and these objectives can only be achieved by changing the farming practices from fossil-based energy generation to renewable energy based farming. Renewable energy technologies to be able to use in farming are solar energy, wind energy, geothermal energy, and biomass energy. IFES is a farming system model designed to combine, intensify, and hence improve the simultaneous production of food and energy through the sustainable use of biomass; achieved in two ways: 1. Combining the production of food and fuel feedstock 
on the same land, e.g. inter-cropping, agroforestry, or agro-pastoral systems, 2. Using the by-products/residues of one production system i.e. 'closed loop' or 'zero waste' systems. Hence, energy-smart solutions can include simultaneously producing food and energy as a means of achieving sustainable production systems in rural communities as shown in Figure 21 (Sims \& Flammini 2014).

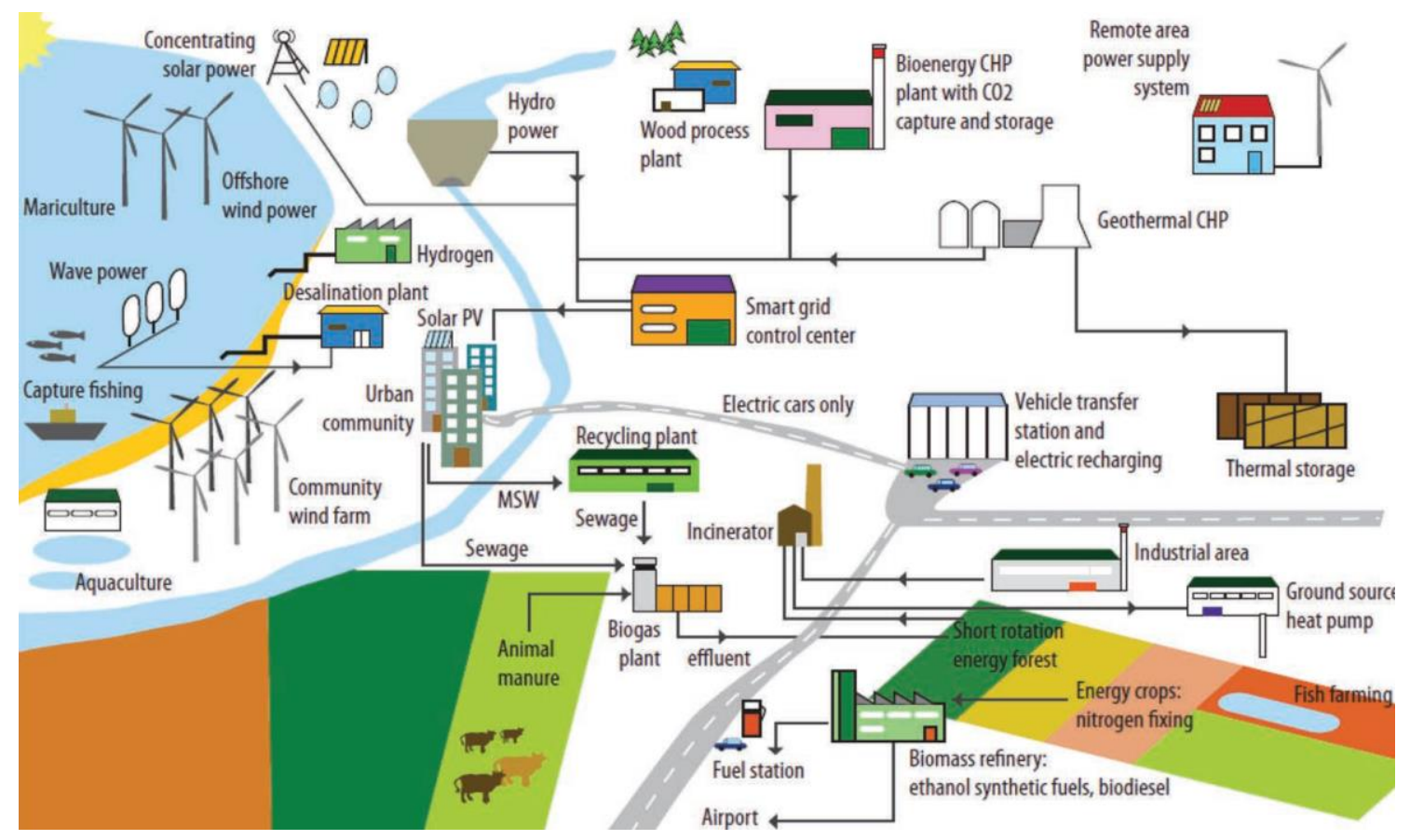

Figure 21- Integrated food energy system (IFES) (Sims \& Flammini 2014)

\section{Discussion}

In this review, innovative digital technologies to be able to use in agri-food systems are discussed based on the water-energyfood nexus for sustainable development. The agriculture sector has a social-economic structure that is always a risky sector, where variable inputs are used to grow very different products such as food and feed, directly affected by weather conditions. Agricultural activities, unlike industry, are carried out in large, open areas like fields, vineyards, and orchards, or closed areas like greenhouses, barns, poultry houses, and mushroom houses. Today, it is necessary to switch from labor-intensive production to technology-intensive production for successful and sustainable agricultural production in all its processes.

Since the areas used in agricultural production are limited, a productivity increase in agricultural production should be ensured. While input costs can be reduced, production yield and quality can be increased using precision farming (Berger 2019; Wolfert et al. 2017) and smart farming (Balafoutis et al. 2019; Boursianis et al. 2019) technologies with variable rate applications, developed applications saving the environment.

The driving factor of smart agriculture is to meet the demand for more food to increase yields, optimize interdependent resources of energy, water, and land, and provide sustainable urbanization. Water and energy are two finite resources that must reach access to more people and so ensuring everyone has access to a reliable supply are crucial to human survival and sustainable development (EC 2017; FAO 2017a; WB 2019).

The agri-food value chain consumes 30 percent of the world's available energy (FAO 2020). Energy is needed in the production of crops, fish, livestock, and forestry products, food storage and processing, food transport and distribution and, as well as, in food preparation (FAO 2012). Although the availability of fossil fuels has made a significant contribution to feeding the world, these energy sources are finite and, in general, environmentally problematic. As discussed also in this study, renewable energy technologies are key to food security and a climate-friendly, sustainable transformation of agri-food systems to produce more and better-quality food. Data-driven systems, IoT-backed sensors keep an eye on consumption patterns and provide insights into inefficient areas which in turn help to analyze energy consumption, usage, and pattern. These solutions can be utilized to manage and optimize energy consumption patterns by taking complete control of energy data at the most fundamental and granular level.

FAO supports digital technologies, innovative ideas with high potential for impact in food and agriculture, for transforming digital solutions and services into global public goods. FAO aims to explore the responsible application and adoption of existing 
and frontier technologies, design and new services, tools and approaches to empower rural households and inspire youth entrepreneurship in food and agriculture (Santos Valle \& Kienzle 2020).

The farming sector is moving towards a new paradigm that is recalled Agriculture 4.0 that integrates a number of innovations in order to produce agricultural products. Agriculture has become a strategic sector that needs to be given more importance due to reasons such as climate imbalances caused by global warming, an increase in the world population, and the gradual decrease of usable agricultural resources. Today, when traditional farming methods are no longer sufficient, countries have to focus on practices that increase productivity and reduce costs with Agriculture 4.0 practices. Smart Agriculture or Agriculture 4.0 is used to point out the digitalization of production as in Industry 4.0. Indeed, modern technology is available that will make agriculture more environmentally friendly and efficient. Technical improvements in the agriculture sector can be carried out to optimize production efficiency, and improve quality, minimize carbon footprint; and can be reduced production-associated risks.

Agricultural applications that are from crop production to harvesting, from weather monitoring to prediction, irrigation, weeding, fertigation, pest control, and logistics are rapidly evolving towards a new digital cosmos covering technologies such as IoT, cloud computing, big data, automation, and artificial intelligence.

\section{Conclusions}

This study targets to obtain holistic solutions in a systematic view, basis on Water-Energy-Food nexus to agricultural digital transformation that will support achieving a sustainable future. Digitalization is a technology accessing unexploited data pools to valuable information, providing transformation to potential benefits for society and the environment if programming smartly and efficiently among data sets.

The water-food-energy resources are at the center of sustainable development. The development of smart systems interconnected can generate unique opportunities to effectively solve the challenges targeted in United Nations' Sustainable Development Goals. It can be emphasized that smart technologies can be able to use as tools for game-rule changing, if setting their systematic integrations, the food-water-energy nexus will benefit sustainable development. The strategical use of three essential sources for future generations will provide invaluable solutions listed here: (1) sustainable food production; (2) access to fresh and safe water; and (3) renewable energy generation and usage. Human beings have two inevitable missions to fulfill sustainable development. The first one is to solve the interconnections between food - water - energy - climate nexus. The second one is to develop smarter machines and systems achieving agricultural transformation from traditional to digital to improve efficiency, decrease input costs and resource use, and protect the environment.

In the new digital era starting with the Industry 4.0 revolution, the production capabilities of all industries thanks to innovations emerged, including agriculture will have to transform in order to feed the rapidly growing population of the world.

Smart agriculture is real-time farm management providing a high degree of automation, and data-driven intelligent decisionmaking to improve productivity, save natural resources. Digital technologies can support farmers' production of safe, sustainable, and quality food. Technological innovations can help us overwhelm many of the economic, social, and environmental challenges that agriculture is facing today. Novel technologies like the internet of things, cloud computing, big data, artificial intelligence, drones, and robotics provide making processes more efficient and drive the creation of new products and services and streamline agricultural operations.

The driven technology of Agriculture 4.0 is the IoT that provides the ability to securely connect end-to-end to anything, to anywhere. In IoT, numerous wireless sensor network deployed to the field can be used along with cloud technologies. Big data gathered site-specific are transformed into meaningful data set to be used in decision support systems for smart applications. The captured information in the field can be examined by computational techniques to reveal trends and patterns, and interactive information on human behaviors, environment, and experiences can be transformed into efficient actions.

By using smart agriculture technologies and data-driven techniques, it will be possible to monitor in real-time how water, chemicals, and energy are used for the production of healthy food and animal feed, and what environmental effects the applied agricultural activity may cause. However, this requires the development of national and international policies, the implementation of strategies, and the control and supervision of processes.

Developed, there are many smart farming technologies including decision support system, yield monitoring, smart irrigation, smart spraying, management of crop disease, crop monitoring, soil monitoring, treatment of pests with robots, intelligent harvesting according to maturity, traceability from farm to fork, logistics, as well as e-marketing. Although innovation is often conceived as techno-centric, the rise of Agriculture 4.0 thinking needs to consider also environmental and social sustainability perspectives. However, challenges related to power, performance, and security are obstacles to seamless connectivity.

Thanks to developments in recent years, it is seen that digital technologies and data-driven techniques have the potential to transform agriculture more precisely, efficiently, and sustainably. Furthermore, while providing greater transparency for 
consumers on how food is produced, decision-making support has helped farmers in many practices, in terms of environmental and agricultural performance. Beyond farming, while digital technologies make the job more attractive to new generations, they offer many opportunities to reduce problems related to remoteness and improve access to services.

Although data-driven technologies play a key role at all stages of the production of food and feed in agri-food systems of the future, none of this can happen without enough energy and water from farm to fork. Being clean and sustainable the energy used in agriculture, not chemically polluted of the water is vital to access to fresh water and clean energy everyone, and for a better reconstructing in the aftermath of the COVID-19 pandemic.

\section{References}

Abegaz B W, Datta T \& Mahajan S M (2018). Sensor technologies for the energy-water nexus - A review. ACS Applied Energy Materials, 210: 451-466. https://doi.org/10.1016/j.apenergy.2017.01.033

Aceto G, Persico V \& Pescape A (2019). A Survey on Information and Communication Technologies for Industry 4.0: State-of-the-Art, Taxonomies, Perspectives, and Challenges, IEEE Commun. Surv. Tutorials, 21(4): 3467-3501. https://doi.org/10.1109/COMST.2019.2938259

Adebanjo D, Laosirihongthong T, Samaranayake P \& Teh P L (2020). Key enablers of industry 4.0 development at firm level: Findings from an emerging economy, IEEE Transactions on Engineering Management. https://doi.org/10.1109/TEM.2020.3046764

Agostini A, Colauzzi M \& Amaducci S (2021). Innovative agrivoltaic systems to produce sustainable energy: An economic and environmental assessment. Applied Energy 281: 116102. https://doi.org/10.1016/j.apenergy.2020.116102

Agrovoltaics (2021). Agrovoltaics a Solar Innovation and Triple usage of Solar Energy. Retrieved in July, 29 , 2021 from https://agrovoltaics.com/index.php

Ahmad L \& Nabi F (2021). Agriculture 5.0. CRC Press, London

Ahmed U, Mumtaz R, Anwar H, Mumtaz S \& Qamar A M (2020). Water quality monitoring: From conventional to emerging technologies. Water Sci. Technol. Water Supply, 20: 28-45. https://doi.org/10.2166/ws.2019.144

Alcon F, Tapsuwan S, Brouwer R, Yunes M, Mounzer O, de-Miguel M D (2019). Modelling farmer choices for water security measures in the Litani river basin in Lebanon. Sci. Total Environ. 647: 37-46. https://doi.org/10.1016/j.ins.2014.10.013

Allardyce C S, Fankhauser C, Zakeeruddin S M, Grätzel M \& Dyson P J. (2017). The influence of greenhouse-integrated photovoltaics on crop production. Solar Energy 155: 517-522. http://dx.doi.org/10.1016/j.solener.2017.06.044

Araújo S O, Peres R S, Barata J, Lidon F \& Ramalho J C (2021). Characterising the Agriculture 4.0 Landscape-Emerging Trends, Challenges and Opportunities. Agronomy 11(667): 1-37. https://doi.org/10.3390/agronomy11040667

Asolkar P \& Bhadade U (2015). An effective method of controlling the greenhouse and crop monitoring using GSM. In: 2015 International Conference on Computing, Communication Control and Automation, February 26 - 27, 2015, Washington pp. 214-219. https://doi.org/10.1109/iccubea.2015.47

ATLAS (2019). Project ATLAS (agricultural interoperability \& analysis system) 2019. Retrieved in July, 1, 2021 from https://www.atlash2020.eu/

Aubert B, Schroeder A \& Grimaudo J (2012). IT as enabler of sustainable farming: an empirical analysis of farmers' adoption decision of precision agriculture technology, Decis. Support Syst. 54: 510-520. https://doi.org/10.1016/j.dss.2012.07.002

Ayaz M, Ammad-Uddin M, Sharif Z, Mansour A \& Aggoune E H (2019). Internet-of Things (IoT)-Based Smart Agriculture: Toward Making the Fields Talk. IEEE Access. 7: 129551-129583. https://doi.org/10.1109/Access.628763910.1109/ ACCESS.2019.2932609

Babatunde O M, Denwigwe I H, Adedoja S O, Babatunde D E \& Gbadamosi S L (2019). Harnessing renewable energy for sustainable agricultural applications. International Journal of Energy Economics and Policy 9(5): 308-315. https://doi.org/10.32479/ijeep.7775

Balafoutis A T, Evert F K V \& Fountas S (2020). Smart Farming Technology Trends: Economic and Environmental Effects, Labor Impact, and Adoption Readiness. Agronomy, 10: 743. https://doi.org/10.3390/agronomy10050743

Bazilian M, Rogner H, Howells M, Hermann S, Arent D \& Gielen D (2011). Considering the energy, water and food nexus: towards an integrated modelling approach. Energy Policy 39: 7896-7906. https://doi.org/10.1016/j.enpol.2011.09.039

Benyezza H, Bouhedda M \& Rebouh, S (2021). Zoning irrigation smart system based on fuzzy control technology and IoT for water and energy saving. Journal of Cleaner Production 302(2021): 127001. https://doi.org/10.1016/j.jclepro.2021.127001

Bera B, Vangala A, Das A K, Lorenz P, Khan M K (2022). Private blockchain-envisioned drones-assisted authentication scheme in IoTenabled agricultural environment, Computer Standards \& Interfaces 80(2022): 103567. https://doi.org/10.1016/j.csi.2021.103567

Berger R (2019). Farming 4.0: How precision agriculture might save the world Precision farming improves farmer livelihoods and ensures sustainable food production. Global Focus Report. Publisher Roland Berger GMBH. Germany

Bieber N, Ker J H, Wang X, Triantafyllidis C, van Dam K H, Koppelaar R H E M \& Shah N (2018). Sustainable planning of the energy-waterfood nexus using decision making tools, Energy Policy 113: 584-607. https://doi.org/10.1016/j.enpol.2017.11.037

Boursianis A D, Papadopoulou M S, Diamantoulakis P, Liopa-Tsakalidi A, Barouchas P, Salahas G, Karagiannidis G, Wan S \& Goudos S K (2020). Internet of Things (IoT) and Agricultural Unmanned Aerial Vehicles (UAVs) in Smart Farming: A Comprehensive Review. Internet of Things. 100187. https://doi.org/10.1016/j.iot.2020.100187

Bundschuh J, Chen G, Tomaszewska B, Ghaffour N, Mushtaq S, Hamawand I, Reardon-Smith K, Maraseni T. Banhazi T H, Mahmoudi M. Goosen \& Antille L D (2017). Solar, wind and geothermal energy applications in agriculture: back to the future? In: J. Bundschuh, G. Chen, D. Chandrasekharam, J. Piechocki (Eds.), Geothermal, Wind and Solar Energy Applications in Agriculture and Aquaculture, London: CRC Press, London pp. 1-32

Cadero A, Aubry A, Dourmad J Y, Salaun Y \& Garcia-Launay F (2018). Towards a decision support tool with an individual-based model of a pig fattening unit. Computers and Electronics in Agriculture 147: 44-50. https://doi.org/10.1016/j.compag.2018.02.012

Carolan M (2018) "Smart" farming techniques as political ontology: access, sovereignty and the performance of neoliberal and not-soneoliberal worlds. Sociol. Rural. 58(4): 745-764. https://doi.org/10.1111/soru.12202

Carolan M (2019). Automated agrifood futures: robotics, labor and the distributive politics of digital agriculture. The Journal of Peasant Studies 1-24. https://doi.org/10.1080/03066150.2019.1584189 
CEMA (2017a). Digital Farming: what does it really mean? Retrieved in July, 1, 2021 from http://www.cema-agri.org/page/digital-farmingwhat-does it-really-mean

CEMA (2017b). Connected Agricultural Machines in Digital Farming. Retrieved in July, 1, 2021 from http://www.cemaagri.org/publication/connectedagricultural-machines-digital-farming

CEMA (2018). Digital farming technology, CEMA association. Retrieved in July, 1, 2021 from https://www.cema-agri.org/digital-farming

Cevher C (2019). Determination of the Main Socio-Economic Factors of the Sustainable Production of Forage Crops: Research of Kayseri Province. Journal of Agricultural Sciences, 25(4):474-480. https://doi.org/10.15832/ankutbd.453983

Chen Y, Li Y \& Li C (2020). Electronic agriculture, blockchain and digital agricultural democratization: Origin, theory and application, Journal of Cleaner Production 268(2020): 122071. https://doi.org/10.1016/j.jclepro.2020.122071

Crippa M, Solazzo, E Guizzardi, D Monforti-Ferrario, F Tubiello F N \& Leip A (2021). Food systems are responsible for a third of global anthropogenic GHG emissions Nature Food 2: 198-209. https://doi.org/10.1038/s43016-021-00225-9)

Daher BT, Hannibal B, Portney KE \& Mohtar RH (2019). Toward creating an environment of cooperation between water, energy, and food stakeholders in San Antonio. Sci. Total Environ. 651(2): 2913-2926. https://doi.org/10.1016/j.scitotenv.2018.09.395

De Clercq M, Vats A \& Biel A (2018). Agriculture 4.0: The future of farming technology, in Proc. World Government Summit, Dubai, 2018, pp. 11-13

DEMETER (2019). Project DEMETER. Retrieved in July, 1, 2021 from https://h2020-demeter.eu/

Eastwood C, Klerkx L, Ayre M \& Dela Rue B (2017). Managing socio-ethical challenges in the development of smart farming: from a fragmented to a comprehensive approach for responsible research and innovation. J Agric Environ Ethics 32: 741-768. https://doi.org/10.1007/s10806-017-9704-5

EC (2017). The Future of Food and Farming. European Commission, Brussels

EC (2019). The contribution of precision agriculture technologies to farm productivity and the mitigation of greenhouse gas emissions in the EU. European Commission Joint Research Center, Brussels

EC (2021a). European Commission Internal Market, Industry, Entrepreneurship and SMEs Advanced Technologies for Industry. Retrieved in July, 1, 2021 from https://ati.ec.europa.eu/technologies

EC (2021b). Shaping Europe's digital future. Large-scale pilots in the digitisation of agriculture. Retrieved in July, 1, 2021 from https://digitalstrategy.ec.europa.eu/en/policies/large-scale-pilots-digitisation-agriculture

EIA (2016). World Energy Outlook. International Energy Agency. Paris, France

EIA (2019). International Energy Outlook 2019 with projections to 2050. Paris, France

ElMassaha S \& Mohieldin M (2020). Digital transformation and localizing the Sustainable Development Goals (SDGs). Ecological Economics 169: 106490. https://doi.org/10.1016/j.ecolecon.2019.106490

FAO (2012). World agriculture towards 2030/2050. FAO of the UN, Rome

FAO (2014). The Water-Energy-Food Nexus - A new approach in support of food security and sustainable agriculture. Food and Agriculture Organization of the United Nations (FAO), Rome

FAO (2016). AQUASTAT Database. Retrieved in July, 29, 2021 from http://www.fao.org/nr/water/aquastat/data/query/index.html?lang=en

FAO (2017a). The future of food and agriculture-trends and challenges. Food and Agriculture Organization of the United Nations, Rome

FAO (2017b). Water for Sustainable Food and Agriculture A report produced for the G20 Presidency of Germany, Food and Agriculture Organization of the United Nations, Rome

FAO (2018). Transforming food and agriculture to achieve the SDGs, FAO, Rome

FAO (2019). FAO's work on climate change, The Food and Agriculture Organization of the United Nations (FAO), Rome

FAO (2020). Emissions due to agriculture. Global, regional and country trends 2000-2018. FAOSTAT Analytical Brief Series, No 18. Rome

FAO (2021). The impact of disasters and crises on agriculture and food security. Rome. https://doi.org/10.4060/cb3673en

Fielke S J, Garrard R, Jakku, E, Fleming A, Wiseman L \& Taylor B M (2019). Conceptualising the DAIS: implications of the 'Digitalisation of Agricultural Innovation Systems' on technology and policy at multiple levels. NJAS-Wageningen J. Life Sci. 90. https://doi.org/10.1016/j.njas.2019.04.002

Fielke S, Taylor B \& Jakku E (2020). Digitalisation of agricultural knowledge and advice networks: a state-of-the-art review. Agricultural Systems 180. https://doi.org/10.1016/j.agsy.2019.102763

Fielke S J, Botha N, Reid J, Gray D, Blackett P, Park N \& Williams T (2018). Lessons for co-innovation in agricultural innovation systems: a multiple case study analysis and a conceptual model. J. Agric. Educ. Ext. 24(1): 9-27. https://doi.org/10.1080/1389224X.2017.1394885

Fleming A, Jakku E, Fielke S, Taylor B M, Lacey J, Terhorst A \& Stitzlein C (2021). Foresighting Australian digital agricultural futures: Applying responsible innovation thinking to anticipate research and development impact under different scenarios. Agricultural Systems 190: 103120. doi.org/10.1016/j.agsy.2021.103120

Flourish (2018). Project Flourish (aerial data collection and analysis, and automated ground intervention for precision farming). Retrieved in July, 1, 2021 from http://flourish-project.eu

Fraunhofer (2021). Aquaculture Photovoltaics (Aqua-PV). Fraunhofer Institute for Solar Energy Systems ISE Retrieved in July, 1, 2021 from https://www.ise.fraunhofer.de/en/business-areas/photovoltaics/photovoltaic-modules-and-power-plants/integratedphotovoltaics/agrivoltaics/aqua-pv.html

García L, Parra L, Jimenez J M, Lloret J \& Lorenz P (2020). IoT Based Smart Irrigation Systems: An Overview on the Recent Trends on Sensors and IoT Systems for Irrigation in Precision Agriculture. Sensors. 20(4): 1042. https://doi.org/10.3390/s20041042

GHD and AgThentic (2018). Emerging agricultural technologies: Consumer perceptions around emerging agtech, Publication No. 18/048, Project No. PRJ-011141, 2018 AgriFutures Australia

Goh C S, Ahl A \& Woo W T (2021). Sustainable Transformation of Land-Based Economic Development in the Era of Digital Revolution, Trends in Biotechnology, 39(1): 1-4. https://doi.org/10.1016/j.tibtech.2020.05.010

Hatfield J L, Boote K J, Kimball B A, Ziska L H, Izaurralde R C, Ort D, Thomson A M \& Wolfe D W (2011). Climate impacts on agriculture: Implications for crop production. Agronomy Journal, 103: 351-370. https://doi.org/10.2134/agronj2010.0303

Hatfield J L \& Prueger J H (2015). Temperature extremes: Effect on plant growth and development. Weather and Climate Extremes. 10: 4-10.

Hoff H (2011). Understanding the Nexus: Background paper for the Bonn 2011 Nexus conference: The Water, Energy and Food Security Nexus. 19-18 Nov. 2011. Bonn

Howells M, Hermann S, Welsch M, Bazilian M, Segerstrom R \& Alfstad T (2013). Integrated analysis of climate change, land-use, energy and water strategies. Nat. Clim. Chang. 3: 621-626. https://doi.org/10.1038/nclimate1789 
IOF2020 (2017). Project INTERNET OF FOOD \& FARM 2020. Retrieved in July, 1, 2021 from https://www.iof2020.eu/

IRENA (2015). Renewable Energy in the Water, Energy and Food Nexus. Abu Dhabi

ISPA (2021). Precision Ag Definition. International Society of Precision Agriculture Retrieved in July, 29, 2021 from https://www.ispag.org/about/definition

Jha K, Doshi A, Patel P \& Shah M (2019). A comprehensive review on automation in agriculture using artificial intelligence. Artificial Intelligence in Agriculture. 2: 1-12. https://doi.org/10.1016/j.aiia.2019.05.004

Kelton K, Fleischmann K R \& Wallace W A (2008). Trust in digital information. J. Assoc. Inf. Sci. Technol. 59(3): 363-374

Keogh M \& Henry M (2016). The Implications of Digital Agriculture and Big Data for Australian Agriculture. Australian Farm Institute, Sydney, Australia

Keyhanpour M J, Jahromi S H M \& Ebrahimi H (2021). System dynamics model of sustainable water resources management using the Nexus Water-Food-Energy approach, Ain Shams Engineering Journal 12: 1267-1281. https://doi.org/10.1016/j.asej.2020.07.029

Kim S, Lee M \& Shin C (2018). IoT-Based Strawberry Disease Prediction System for Smart Farming. Sensors 18(11): 4051-4067. https://doi.org/10.3390/s18114051

Klerkx L \& Begemann S (2020). Supporting food systems transformation: the what, why, who, where and how of mission-oriented agricultural innovation systems. Agric. Syst. 184: 102901. https://doi.org/10.1016/j.agsy.2020.102901

Klerkx L \& Rose D (2020). Dealing with the game-changing technologies of Agriculture 4.0: how do we manage diversity and responsibility in food system transition pathways? Global Food Security 24: 100347. https://doi.org/10.1016/j. gfs.2019.100347

Klerkx L, Jakku E \& Labarthe P (2019). A review of social science on digital agriculture, smart farming and agriculture 4.0: new contributions and a future research agenda. NJAS - Wageningen J. Life Sci. 90-91: 100315. https://doi.org/10.1016/j.njas.2019.100315

Klerkx L, Seuneke P, de Wolf P \& Rossing W A (2017). Replication and translation of co-innovation: the influence of institutional context in large international participatory research projects. Land Use Policy 61: 276-292. https://doi.org/10.1016/j.landusepol.2016.11.027

Knight C H (2020). Sensor techniques in ruminants_ more than fitness trackers. Animal 14:187-195. doi:10.1017/S1751731119003276

Kochhar A \& Kumar N (2019). Wireless sensor networks for greenhouses: An end-to-end review. Computers and Electronics in Agriculture, 163: 104877-104891. https://doi.org/10.1016/j.compag.2019.104877

Kour V P \& Arora S (2020). Recent developments of the Internet of Things in Agriculture: A Survey. IEEE Access 8: 129924-129957. https://doi.org/10.1109/ Access.628763910.1109/ACCESS.2020.3009298

Lee J (2019). AgTech trends in 2019: Precision Agriculture, and Millennial Farmers. G2 Crowd learning Hub.3 Dec. 2019

Lehmann S (2018). Implementing the urban nexus approach for improved resource efficiency of developing cities in Southeast-Asia. City Cult. Soci., 13: 46-56. https://doi.org/10.1016/j.ccs.2017.10.003

Lezoche M, Hernandez J, Diaz M D M A, Panetto H \& Kacprzyk J (2020). Agri-food 4.0: A survey of the supply chains and technologies for the future agriculture. Comput. Ind. 117: 103187-103201. https://doi.org/10.1016/j.compind.2020.103187

Li H M, Wang X C, Zhao X F \& Qi Y (2021). Understanding systemic risk induced by climate change, Advances in Climate Change Research, 12: 384-394. https://doi.org/10.1016/j.accre.2021.05.006

Liakos KG, Busato P, Moshou D, Pearson S \& Bochtis D (2018). Machine learning in agriculture: A review. Sensors, 18(2674): 1-29. https://doi.org/10.3390/s18082674

Liao M S, Chena S F, Chou C Y, Chen H Y, Yeh S H, Chang Y C \& Jiang J A (2017). On precisely relating the growth of Phalaenopsisleaves to greenhouse environmental factors by using an IoT-based monitoring system Computers and Electronics in Agriculture 136: 125-139. https://doi.org/10.1016/j.compag.2017.03.003

Lin N, Wang X, Zhang Y, Hu X \& RuanJ (2020). Fertigation management for sustainable precision agriculture based on Internet of Things. Journal of Cleaner Production 277: 124119. https://doi.org/10.1016/j.jclepro.2020.124119

Lioutas E D, Charatsari C \& De Rosa M (2021). Digitalization of agriculture: A way to solve the food problem or a trolley dilemma? Technology in Society 67(2021): 101744. https://doi.org/10.1016/j.techsoc.2021.101744

Liu Y, Ma X, Shu L, Hancke G P, Abu-Mahfouz A M (2021). From Industry 4.0 to Agriculture 4.0: Current Status, Enabling Technologies, and Research Challenges. IEEE Transactions on Industrial Informatics, 17(6): 4322-4334. https://doi.org/10.1109/TII.2020.3003910

Lorentz (2012). Solar powered vineyard irrigation system. Chile Case Study 4, 09|2012 Retrieved in July, 29 , 2021 from https://partnernet.lorentz.de/files/lorentz_casestudy_vineyardlurton_chile_en-en.pdf

Lorentz (2014). Solar Water Pumping for Center Pivot Irrigation. North Africa Case Study 7, 05|2014. Retrieved in July, 29,2021 from https://partnernet.lorentz.de/files/lorentz_casestudy_pivot_north_africa_en-en.pdf

Marolia A, Narwanea V S \& Gardas B B (2021). Applications of IoT for achieving sustainability in agricultural sector: A comprehensive review, Journal of Environmental Management 298: 113488. https://doi.org/10.1016/j.jenvman.2021.113488

McBratney A, Whelan B, Ancev T \& Bouma J (2005). Future directions of precision agriculture, Precision Agriculture 6: 7-23. https://doi.org/10.1007/s11119-005-0681-8

Mohtar R H \& Daher B (2016). Water-energy-food nexus framework for facilitating multi stakeholder dialogue. Water Int. 41(5): 655-661. https://doi.org/10.1080/02508060.2016.1149759

Moysiadis V, Sarigiannidis P Vitsas V \& Khelifi A (2021). Smart Farming in Europe. Computer Science Review 39 : 100345. https://doi.org/10.1016/j.cosrev.2020.100345

Namany S, Govindan R, Di Martino M, Pistikopoulos E N, Linke P, Avraamiou S \& Al-Ansari T (2021). An energy-water-food nexus-based decision-making framework to guide national priorities in Qatar. Sustainable Cities and Society 75: 103342. https://doi.org/10.1016/j.scs.2021.103342

Newton J E, Nettle R \& Pryce J E (2020). Farming smarter with big data: Insights from the case of Australia's national dairy herd milk recording scheme, Agricultural Systems 181: 102811. https://doi.org/10.1016/j.agsy.2020.102811

Norouzi N \& Kalantari G (2020). The food-water-energy nexus governance model: A case study for Iran, Water-Energy Nexus 3: 72-80

OECD (2012). OECD Environmental Outlook to 2050: The Consequences of Inaction. https://doi.org/10.1787/9789264122246-en

Ojha T, Misra S, Raghuwanshi NS (2015). Wireless sensor networks for agriculture: The state-of-the-art in practice and future challenges. Computer and Electronic in Agriculture, 118: 66-84 https://doi.org/10.1016/j.compag.2015.08.011

Pedersen S M \& Lind K M (2017). Precision Agriculture: Technology and Economic Perspectives, Springer, Switzerland

Platis D, Anagnostopoulos C, Tsaboula A, Menexes G, Kalburtji K \& Mamolos A (2019). Energy analysis, and carbon and water footprint for environmentally friendly farming practices in agroecosystems and agroforestry. Sustainability 1664 . https://doi.org/10.3390/su11061664 
Pringle A M, Handler R M \& Pearce J M (2017). Aquavoltaics: synergies for dual use of water area for solar photovoltaic electricity generation and aquaculture. Renewable and Sustainable Energy Reviews. 80: 572-84. https://doi.org/10.1016/j.rser.2017.05.191

Purwanto A, Susnik J, Suryadi FX \& de Fraiture C (2019). Using group model building to develop a causal loop mapping of the water-energyfood security nexus in Karawangregency, Indonesia. J. Clean. Prod. 240: 118170. https://doi.org/10.1016/j.jclepro.2019.118170

pv magazine (2020). Premiers résultats de l'expérimentation agrivoltaïque de Sun'Agri à Piolenc. Retrieved in July, 29, 2021 from https://www.pvmagazine.fr/2020/03/31/premiers-resultats-de-lexperimentation-agrivoltaique-de-sunagri-a-piolenc/?utm_source=dlvr.it\&utm_medium=twitter

pv magazine (2021). India's largest floating solar plant commissioned. Retrieved in July, 29, 2021 from https://www.pv-magazineaustralia.com/2021/09/20/indias-largest-floating-solar-plant-commissioned/

PV TECH (2020). BayWa r.e. starts building 27.4MWp floating PV plant on Dutch lake. Retrieved in July, 29, 2021 from https://www.pvtech.org/news/baywa-r.e.-starts-construction-of-27.4mwp-plant-on-dutch-sandpit-lake

Pylianidis C, Osinga S \& Athanasiadis IN (2021). Introducing digital twins to agriculture, Computers and Electronics in Agriculture 184, 105942. https://doi.org/10.1016/j.compag.2020.105942

Raj M, Gupta S, Chamola V, Elhence A, Garg T, Atiquzzaman M \& Niyato D (2021). A survey on the role of Internet of Things for adopting and promoting Agriculture 4.0. Journal of Network and Computer Applications 187: 10310. https://doi.org/10.1016/j.jnca.2021.103107

Rasul G \& Sharma B (2016). The nexus approach to water energy food security: An option for adaptation to climate change an option foradaptation to climate change. Climate Policy 16(6): 682-702. https://doi.org/10.1080/14693062.2015.1029865

Ravar Z, Zahraie B, Sharifinejad A, Gozini H \& Jafari S (2020). System dynamics modeling for assessment of water-food-energy resources security and nexus in Gavkhuni basin in Iran. Ecological Indicators 108: 105682. https://doi.org/10.1016/j.ecolind.2019.105682105682

Regan Á (2019). 'Smart farming' in Ireland: a risk perception study with key governance actors. NJAS - Wageningen J. Life Sci 90-91: 100292. https://doi.org/10. 1016/j.njas.2019.02.003

Rijswijk K, Klerkx L, Bacco M, Bartolini F, Bulten E, Debruyne L, Dessein J, Scotti I \& Brunori G (2021). Digital transformation of agriculture and rural areas: A socio-cyber-physical system framework to support responsibilisation, Journal of Rural Studies 85: 79-90. https://doi.org/10.1016/j.jrurstud.2021.05.003

Roidt M \& Avellán T (2019). Learning from integrated management approaches to implement the nexus. J. Environ. Manag 237: 609-616. https://doi.org/10.1016/j.jenvman.2019.02.106

ROMI (2020). Project ROMI (RObotics for MIcrofarms). Retrieved in July, 1, 2021 from https://romi-project.eu

Rose D C \& Chilvers J (2018). Agriculture 4.0: Broadening responsible innovation in an era of smart farming, Frontiers in Sustainable Food System 2(87): 1-6. https:// doi.org/10.3389/fsufs.2018.00087

Rose D C, Wheeler R, Winter M, Lobley M \& Chivers CA (2021). Agriculture 4.0: Making it work for people, production, and the planet. Land Use Policy 100: 104933. https://doi.org/10.1016/j.landusepol.2020.104933

Roy S K, Misra S, Raghuwanshi N S \& Das S K (2021). AgriSens: IoT-based dynamic irrigation scheduling system for water management of irrigated crops, IEEE Internet Things J., 8(6): 5023-5030. https://doi.org/10.1109/JIOT.2020.3036126

Sachs J D, Schmidt-Traub G, Mazzucato M, Messner D, Nakicenovic N \& Rockström J (2019). Six Transformations to achieve the Sustainable Development Goals, Nature Sustainability 2: 805-814. https://doi.org/10.1038/s41893-019-0352-9

Sadowski S \& Spachos P (2020). Wireless technologies for smart agricultural monitoring using internet of things devices with energy harvesting capabilities. Computers Electronics in Agriculture 172: 105338-105347. https://doi.org/10.1016/j.compag.2020.105338

Santos Valle S \& Kienzle J (2020). Agriculture 4.0 - Agricultural robotics and automated equipment for sustainable crop production. Integrated Crop Management Vol. 24. Rome, FAO

Say M S, Keskin M, Sehri M \& Sekerli Y E (2017). Adoption of precision agriculture technologies in developed and developing countries. International Science and Technology Conference (ISTEC), July 17-19, 2017 Berlin, Germany, August 16-18 Cambridge, USA

Schwab K (2015) The fourth Industrial revolution: What it means and how to respond, Foreign Affairs. Retrieved in July, 1, 2021 from https://www.foreignaffairs.com/articles/2015-12-12/fourth-industrial-revolution

Shepherd M, Turner J A, Small B \& Wheeler D (2018). Priorities for science to overcome hurdles thwarting the full promise of the 'digital agriculture' revolution. J. Sci. Food Agric. https://doi.org/10.1002/jsfa.9346

Sims R E H \& Flammini A (2014). Chapter 6: Energy-smart food - technologies, practices and policies pp: 123-169, In: Sustainable Energy Solutions in Agriculture, Editors: Jochen Bundschuh, Guangnan Chen, CRC Press, London

Sinha B B \& Dhanalakshmi R (2022). Recent advancements and challenges of Internet of Things in smart agriculture: A survey. Future Generation Computer Systems 126(2022): 169-184. https://doi.org/10.1016/j.future.2021.08.006

Sligo F X \& Massey C (2007). Risk, trust and knowledge networks in farmers' learning. J. Rural. Stud 23(2): 170-182. https://doi.org/10.1016/j.jrurstud.2006.06.001

Solaripedia (2021). Green Architecture \& Building. Retrieved in July, 29, 2021 from http://www.solaripedia.com/13/147/wineries_and_thieves_go_solar_(california,_usa).html

Solarvibes (2021). Solar-powered Plug \& Play Farm Monitoring System. Retrieved in July, 29, 2021 from https://www.solar-vibes.com/

Soto I, Barnes A, Balafoutis A, Beck B, Sanchez B, Vangeyte J, Fountas S, Van der Wal T, Eory V \& Gómez-Barbero M (2019) The contribution of Precision Agriculture Technologies to farm productivity and the mitigation of greenhouse gas emissions in the EU, EUR (where available), Publications Office of the European Union, Luxembourg. https://doi.org/10.2760/016263, JRC112505

Talepbour B, Türker U \& Yegül U (2015). The Role of Precision Agriculture in the promotion of Food Security. International Journal of Agricultural and Food Research-Science target. 4(1): 1-23. https://doi.org/10.24102/ijafr.v4i1.472

Tao W, Zhao L, Wang G \& Liang R (2021). Review of the internet of things communication technologies in smart agriculture and challenges. Computers and Electronics in Agriculture 189(2021): 106352 https://doi.org/10.1016/j.compag.2021.106352

Tian H, Lu C, Pan C, Yang J, Miao R, Ren W, Yu Q, Fu B, Jin F, Lu Y, Melillo J, Ouyang Z, Palm C \& Reilly J (2018) Optimizing resource use efficiencies in the food-energy-water nexus for sustainable agriculture: from conceptual model to decision support system. Current Opinion in Environmental Sustainability, 33: 104-113. https://doi.org/10.1016/j.cosust.2018.04.003

Trendov N M, Varas S \& Zeng M (2019). Digital technologies in agriculture and rural areas - Status Report. Food and Agriculture Organization of the United Nations (FAO), Rome

TWI2050 (2018). Transformations to Achieve the Sustainable Development Goals, International Institute for Applied Systems Analysis. Laxenburg, Austria

Tzounis A, Katsoulas N, Bartzanas T \& Kittas C (2017). Internet of Things in agriculture, recent advances and future challenges. Biosystems Engineering. 164: 31-48. https://doi.org/10.1016/j.biosystemseng.2017.09.007 
UNECE (2021). Water-food-energy-ecosystem nexus (The United Nations Economic Commission for Europe. Retrieved in July, 1, 2021 from https://unece.org/environment-policy/water/areas-work-convention/water-food-energy-ecosystem-nexus)

United Nations (2015). Transforming our world: The 2030 agenda for sustainable development. In: United Nations General Assembly; Seventieth Session. September 18, New York, NY

Vaintrub M O, Levit H, Chincarini M, Fusaro I, Giammarco M \& Vignola G (2021). Precision livestock farming, automats and new technologies: possible applications in extensive dairy sheep farming, Animal 15(2021): 100143. https://doi.org/10.1016/j.animal.2020.100143

VINBOT (2017). Project VINBOT (Autonomous Cloud-Computing Vineyard Robot to Optimize Yield Management and Wine Quality). Retrieved in July, 1, 2021 from http://vinbot.eu

VINEROBOT (2017). Project VINEROBOT (VINEyardROBOT). Retrieved in July, 1, 2021 from http://www.vinerobot.eu

WB (2017). ICT in Agriculture: Connecting Smallholders to Knowledge, Networks, and Institutions, Updated Edition. World Bank Washington, DC

WB (2019). Future of Food Harnessing Digital Technologies to Improve Food System Outcomes. World Bank Washington, DC.

Wolfert S, Ge L, Verdouw C \& Bogaardt M J (2017). Big data in smart farming-A review, Agricultural Systems 153: 69-80. http://dx.doi.org/10.1016/j.agsy.2017.01.023

Yue Q, Wu H, Wang Y \& Guo P (2021). Achieving sustainable development goals in agricultural energy-water-food nexus system: An integrated inexact multi-objective optimization approach, Resources. Conservation \& Recycling 174: 105833. https://doi.org/10.1016/j.resconrec.2021.105833

Yue Q \& Guo P (2021). Managing agricultural water-energy-food-environment nexus considering water footprint and carbon footprint under uncertainty, Agricultural Water Management 252: 106899. https://doi.org/10.1016/j.agwat.2021.106899

Yurtseven, E., Colak, M.S., Ozturk, A. \& Ozturk, H.S. (2018). Drainage Water Salt Load Variations Related to the Salinity and Leaching Ratios of Irrigation Water. Journal of Agricultural Sciences, 24(3):394-402. https://doi.org/10.15832/ankutbd.456667

Yülek M A (2018). The industrialization process: A streamlined version. In: How Nations Succeed: Manufacturing, Trade, Industrial Policy, and Economic Development. Springer Heidelberg, Germany, pp. 171-182

Zambon I, Cecchini M, Egidi G, Saporito M G \& Colantoni A (2019). Revolution 4.0: Industry vs. agriculture in a future development for SMEs. Processes 7(36): 1-16. https://doi.org/10.3390/pr7010036

Zamora-Izquierdo M A, Santa J, Martinez J A, Martinez V \& Skarmeta A F (2019). Smart farming IoT platform based on edge and cloud computing. Biosystems Engineering. 177: 4-17. https://doi.org/10.1016/j.biosystemseng.2018.10.014

Zhai Z, Martínez J F, Beltran V \& Martínez N L (2020). Decision support systems for agriculture 4.0: Survey and challenges. Computer Electronics and Agriculture. 170: 105256: 1-16. https://doi.org/10.1016/j.compag.2020.105256

Zhang X \& Vesselinov V V (2016). Energy-water nexus: Balancing the tradeoffs between two-level decision makers. Appl. Energy 183: 7787. https://doi.org/10.1016/j.apenergy.2016.08.156

Zhang C, Chen X X, Li Y, Ding W \& Fu G T (2018). Water-energy-food nexus: concepts, questions and methodologies. J. Clean. Prod. 195: 625-639. https://doi.org/10.1016/j.jclepro.2018.05.194

Zhang M, Wang X, Feng H, Huang Q, Xiao X \& Zhang X (2021). Wearable Internet of Things enabled precision livestock farming in smart farms: A review of technical solutions for precise perception, biocompatibility, and sustainability monitoring. Journal of Cleaner Production 312: 127712. https://doi.org/10.1016/j.jclepro.2021.127712

(C) 2021 by the authors. Licensee Ankara University, Faculty of Agriculture, Ankara, Turkey. This article is an open access article distributed under the terms and conditions of the Creative Commons Attribution (CC BY) license (http://creativecommons.org/licenses/by/4.0/). 